\section{NOVA TELLVS}

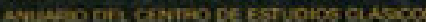

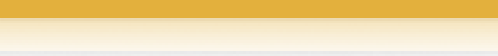

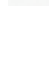

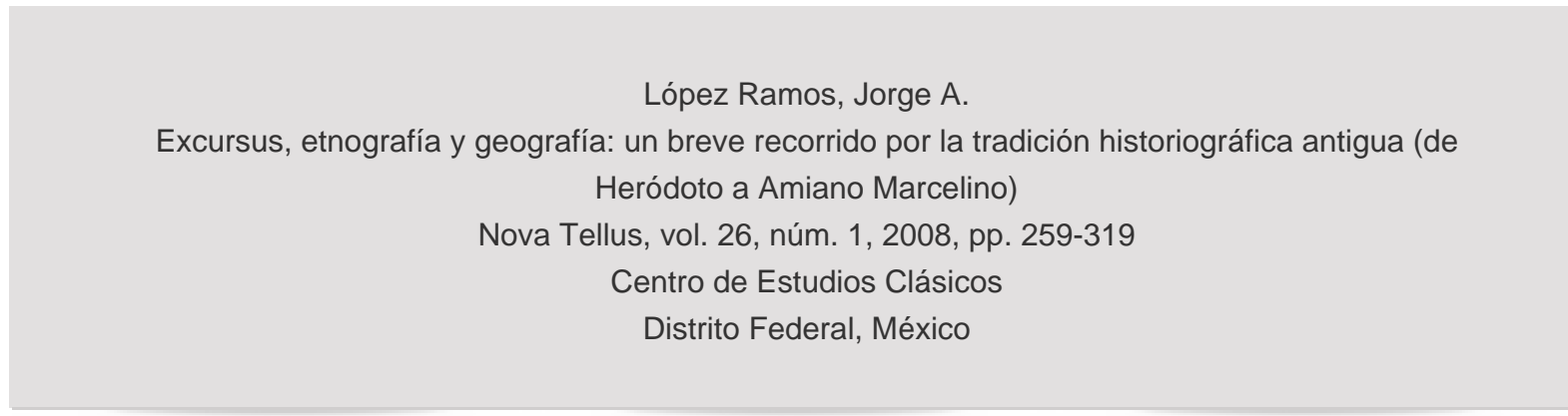

Disponible en: http://www.redalyc.org/articulo.oa?id=59115488009

- Cómo citar el artículo

- Número completo

- Más información del artículo

- Página de la revista en redalyc.org

\section{novatelu@servidor.unam.mx \\ Centro de Estudios Clásicos \\ México \\ Nova Tellus \\ SSN: 0185-3058}




\title{
Excursus, etnografía y geografía: un breve recorrido por la tradición historiográfica antigua (de Heródoto a Amiano Marcelino)
}

\author{
Jorge A. LÓPEZ RAMOS \\ Universidad Nacional Autónoma de México \\ dtexeiras@hotmail.com
}

\begin{abstract}
RESUMEN: En este artículo se analizan las digresiones etnográfico-geográficas de las Res Gestae de Amiano Marcelino. Este autor, heredero de una larga tradición historiográfica que se remonta hasta Heródoto, lo es asimismo de la tradición etnográfica y geográfica que tiene sus orígenes en los periplos griegos, que fue luego sistematizada en época helenística, para finalmente pasar al género historiográfico romano. Así pues, se explicará el empleo de toda esa información por parte de Amiano Marcelino como una probable síntesis de las tradiciones histórica, literaria y científica.
\end{abstract}

$$
* * *
$$

ABSTRACT: The ethnographical and geographical digressions of Ammianus Marcellinus' Res Gestae are examined in this paper. This writer, who was heir to a long historiographical tradition going back to Herodotus, belongs also to the ethnographical and geographical tradition that originated in the Greek periplus accounts. This literary genre was then systematically consolidated in Hellenistic times, whence the Roman historiography drew a lot of inspiration. Ammianus Marcellinus use of all those informations will be accounted for as a probable synthesis of historical, literary and scientific traditions.

PALABRAS CLAVE: Amiano Marcelino, excursus, geografía, historia. RECEPCIÓN: 3 de marzo de 2008.

ACEPTACIÓN: 2 de mayo de 2008. 


\title{
Excursus, etnografía y geografía: un breve recorrido por la tradición historiográfica antigua (de Heródoto a Amiano Marcelino)
}

\author{
Jorge A. LóPEZ RAMOS
}

\section{Introducción}

Según una definición moderna la digresión es "una interrupción justificada del hilo temático del discurso, dándole un desarrollo inesperado con el objeto de narrar una anécdota..., describir un paisaje, un objeto, una situación, etc., en forma extensa, antes de retomar la materia que se venía tratando". ${ }^{1}$ Esta definición no es muy distinta de la que dio Quintiliano en su época: П $\rho \varepsilon_{\kappa} \beta \alpha \sigma ı \varsigma$ est, ut mea quidem fert opinio, alicuius rei, sed ad utilitatem causae pertinentis extra ordinem excurrens tractatio. ${ }^{2}$

Si nos enfocamos en la extensión de la digressio, la teoría insiste en que ésta no debe prolongarse en extremo, pues rompería la unidad del discurso y parecería que no es necesaria ni oportuna. En cuanto a su naturaleza, la digresión puede adoptar la forma de una licencia, un apóstrofe o una descripción. En los textos de la antigüedad, si bien es cierto que la digresión fue concebida como una narración particular que interrumpe el relato central, en rigor también otros elementos estilísticos como los discursos, el retrato de caracteres e incluso los

\footnotetext{
${ }^{1}$ Helena Beristáin, Diccionario de Retórica y Poética, s. v. "digresión”.

${ }^{2}$ Quint., IV, 3, 14. Los nombres dados a la digresión eran ya muy diversos

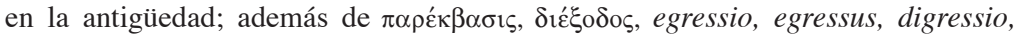
digressus y excursus.
}

261 NOVA TELLVS, 26•1, 2008 
exempla constituyen excursus que se apartan de una narración determinada. ${ }^{3}$

El excursus o digresión es uno de los componentes retóricos más característicos de la literatura antigua en general y del género historiográfico en particular. Su empleo, recurrente, a lo largo de la tradición literaria antigua ha hecho del excursus una pieza de valor intrínseco. No obstante, esto no significa que tengamos que desligarlo de su contexto, por el contrario su importancia estriba en gran medida en la función que ejerce dentro de una narración determinada. Digresiones de índole científica, literaria, filosófica, religiosa, mitológica, social, política y moral han sido desarrolladas profusamente por los escritores de la antigüedad. Dentro de toda esta gama de posibilidades el excursus etnográfico-geográfico ha tenido presencia en diversos géneros literarios como la épica, la poesía didáctica, la novela, la literatura científica y especialmente la historiografía.

Por el número, la variedad temática y la extensión de las digresiones que contiene, ${ }^{4}$ la obra histórica Res Gestae de

\footnotetext{
${ }^{3}$ M. Martínez Pastor, “Amiano Marcelino, escritor romano”, p. 98.

${ }^{4}$ Existen diferentes posturas en cuanto al número de digresiones de la obra. Desde los inicios del siglo Xx se establecieron veintiséis; sin embargo, recientemente se ha definido con mayor rigurosidad el concepto de excursus. En efecto, se exige que cada una de estas piezas incluya una fórmula introductoria en la que se exponga el tema a tratar, así como una conclusión que permita regresar al relato central (cf. H. Cichocka, "Die Konzeption des Exkursus im Geschichtswerk des Ammianus Marcellinus”, Eos, 63, 1975, pp. 329-340, quien se encarga de definir de esta manera el excursus. No obstante, ya Quintiliano (IX, 3, 87) registra el tér-

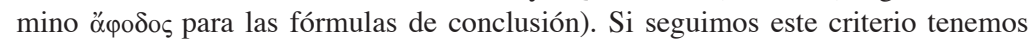
que sólo veintitrés digresiones lo cumplen plenamente. Y como siempre es de esperarse, existen otras opiniones: A. Emmett, "The digressions in the Lost Books of Ammianus Marcellinus", en History and Historians in Late Antiquity, ed. by Croke, B. and Emmett, A. M., Sydney, 1983, pp. 42-53, considera excursus otros pasajes que no tienen ni introducción ni conclusión. En total cuenta treinta y cuatro. Por su parte, T. D., Barnes, Ammianus Marcellinus and the Representation of Historical Reality, Ithaca-London, 1998, agrupa todos aquellos pasajes en los que Amiano, sin "llamar" propiamente a un excursus, indica que tratará algún asunto brevemente. Con ese criterio, Barnes considera treinta y uno. Por otro lado, Cichocka,
} 
Amiano Marcelino, autor sirio nacido en el primer tercio del
siglo IV d.n.e., ${ }^{5}$ brinda una buena oportunidad para discutir las
cuestiones que atañen a la construcción de los excursus, en
concreto su estructura, función, contenido y pertinencia dentro

op. cit., p. 331, afirma que son veinticinco. Por mi parte, comparto la opinión de este último comentarista, pues la colocación explícita de introducciones y conclusiones es la mejor indicación de la existencia de un excursus. Sin embargo, incluyo *tres piezas que no poseen tales fórmulas por tener características afines al resto. Asímismo, en lo sucesivo haré mención de un pasaje con una estructura muy similar a las digresiones que sí han sido consideradas). Por otro lado, los excursus se encuentran casi en toda la obra, con excepción de tres libros, y cada una con una temática muy distinta. No obstante, a partir de H. Finke, Ammianus Marcellinus und seine Quellen zur Geschichte der römischen Republik, Diss. Heidelberg, 1904 (citado por E. Galletier y J. Fontaine, Ammien Marcellin Histoire, XIV-XVI, Paris, Société Guillaume Budé-Les Belles Lettres, 1968, p. 28) existe una tendencia a agruparlas en cuatro categorías: digresiones etnográfico-geográficas, sobre quaestiones naturales, filosófico-religiosas y sociales. En general, y tomando en cuenta la división de la obra a partir del Renacimiento, la extensión de las digresiones es muy variable. Algunas son muy breves y no ocupan más que unos cuantos parágrafos, como las filosófico-religiosas; en cambio, otras pueden abarcar hasta un capítulo de distintas proporciones como es el caso de las etnográfico-geográficas. A continuación una lista de los excursus:

ETNOGRÁFICO-GEOGRÁFICAS: Incursiones de los Isaurios 14.2*/ Los sarracenos 14.4 / Las provincias de oriente 14.8 / El lago Constanza 15.4.1-6 / La Galia 15.9-12 / Asedio de Amida 18.9* / El paso del Suco 21.10.2-4 / Tracia y el Ponto Euxino 22.8.1-48 / Egipto 22.15-16 / Persia 23.6.1-84 / Tracia 27.4 / Los hunos y los alanos 31.2.

QUAESTIONES NATURALES: Los obeliscos y los jeroglíficos $17.4^{*} /$ Los temblores de tierra 17.7.9-14 / Eclipses de sol 20.3 / El arco en el cielo 20.11.26-30 / Las máquinas de asedio 23.4 / Las perlas 23.6.85-88 / Los meteoros 25.2.5-6 / Los cometas 25.10.2-3 / El día bisiesto 26.1.8-14.

Filosófico-RELIGIOSOS: Adrastea o Némesis 14.11.25-26 / La predicción del futuro 21.1.7-14 / Presagios de la muerte de Constancio o el genius 21.14.

Sociales: Vida en Roma 14.6.2-26 / Las causas de la peste 19.4.2-7 / Vicios del senado y del pueblo 28.4.6-35 / Abogados en oriente 30.4.4-22.

Para una exposición más amplia de cada uno de los excursus, cf. Jorge A. López Ramos, El método historiográfico de Amiano Marcelino: El excursus etnográficogeográfico en las Res Gestae (Tracia y el Mar Negro 22.8.1-48), México, Universidad Nacional Autónoma de México [tesis de licenciatura], 2005, pp. 41-53.

${ }^{5}$ Para los pormenores de la vida y la obra de este autor, cf. Jorge A. López Ramos, op. cit., pp. 5-34. 
de la obra histórico-literaria. ${ }^{6}$ Comencemos con el debate que ha ocasionado entre la crítica filológica la presencia de estos "trozos" literarios en la obra de Amiano Marcelino.

Las digresiones etnográfico-geográficas de las Res Gestae fueron objeto de estudio por primera vez por parte de Viktor Gardthausen y Theodor Mommsen. ${ }^{7}$ Por desgracia los juicios desfavorables de Mommsen hacia el excursus perduraron muchas décadas. Incluso en los últimos años las ideas de Mommsen se han dejado escuchar entre los comentaristas de Amiano Marcelino; consecuencia de ello es que las digresiones hayan sido víctima de un enorme desinterés que apenas con algunos esfuerzos -en el caso de las etnográfico-geográficas - se ha intentado revertir en la época más reciente. ${ }^{8}$ No obstante, el desprestigio que ganó el resto de las digresiones desde un primer momento no ha logrado desaparecer por completo. De esta manera, las opiniones en torno al excursus permiten apreciar una tendencia que, con escasas excepciones, puede señalarse como negativa.

La crítica señala que estos episodios tienen una extensión desmesurada y que con frecuencia carecen de un vínculo sólido con el resto de la narración. ${ }^{9}$ Además, tiende a preferir la crónica histórica en detrimento de las digresiones, asegurando

\footnotetext{
${ }^{6}$ Nos concentramos en las siguientes líneas únicamente en las digresiones etnográfico-geográficas por dos razones: por ser a nuestro juicio las que revisten mayor interés y porque en la segunda parte de este artículo realizaremos algunos comentarios sobre la geografía conceptual, verdadero objetivo de nuestro análisis.

${ }^{7}$ Cf. V. Gardthausen, Die geographischen Quellen Ammians, Jb. f. class. Philol., Suppl. 6, Leipzig, 1873 y el célebre artículo de Theodor Mommsen, “Ammians Geographica”, Hermes, 16 (1881), pp. 602-636.

${ }^{8}$ La revaloración de esta clase de excursus ha sido realizada fundamentalmente por investigadores holandeses y estadounidenses. Importantes en este sentido son los comentarios de Jan Willen Drijvers ("Ammianus Marcellinus on the Geography of the Pontus Euxinus", 1998), así como el de Gavin Sundwall ("Ammianus Geographicus", 1996, pp. 619-643). Por otra parte, como tendremos oportunidad de observar, Sundwall sigue las tesis propuestas por los geógrafos conceptuales como Richard Talbert.

${ }^{9}$ E. Galletier y J. Fontaine, op. cit., p. 28. Martínez Pastor, op. cit., p. 97.
} 
que su información es de segunda mano y por ello no resulta fidedigna la mayoría de las veces. ${ }^{10}$ John C. Rolfe ejerce una crítica aún más severa al aducir que Amiano no consigue su ideal de veracidad en las digresiones; afirma que ello se debe en parte al poco conocimiento del historiador en los asuntos que toca y en parte a su deseo de ocultar la enorme dependencia de fuentes literarias. ${ }^{11}$ Este mismo autor se lamenta de que Amiano no haya prestado atención a la advertencia de Tito Livio contra los excursus; de haberlo hecho la obra hubiera conseguido mayor uniformidad. Incluso declara que si los excursus se omitieran, el relato no sufriría daño alguno. ${ }^{12}$

Marcelo Martínez Pastor, por su parte, también emite un juicio desfavorable con respecto a las digresiones. En primer lugar, afirma que la intención de Amiano es hacer de ellas una enciclopedia. ${ }^{13}$ Además, para él es la parte de la obra con menor valor literario, en gran medida porque depende de otras fuentes. Asegura que los excursus en todo momento interfieren en la narración y de esa manera rompen su unidad. Concluye que dentro de las digresiones Amiano caracteriza a los pueblos bárbaros con rasgos que demuestran poca habilidad y resultan muy exagerados. ${ }^{14}$

Es probable que Guy Sabbah haya sido uno de los primeros críticos en advertir cualidades específicas en los excursus. Las digresiones tienen además de su función ornamental y de relajación entre dos pasajes de tensión un sentido y una utilidad

\footnotetext{
${ }^{10}$ Michael von Albrecht, Historia de la literatura romana, p. 1294.

${ }^{11}$ Ammianus Marcellinus, ed. by Rolfe, J. C., p. XIX.

${ }^{12}$ Cf. Liv., IX, 17, 1. W. Hamilton y A. Wallace-Hadrill, Ammianus Marcellinus. The Late Roman Empire (A.D. 354-378), Harmondsworth, 1986, siguen al pie de la letra el comentario de J. Rolfe, pues dejan fuera de su traducción todos los excursus.

${ }^{13}$ Martínez Pastor, op. cit., p. 97.

${ }^{14}$ Martínez Pastor, op. cit., p. 110: "Amiano se preocupa por amontonar toda clase de conocimientos; así fomenta una erudición vacía y estéril en todos los campos del saber". En su momento tendremos oportunidad de demostrar que este juicio del crítico es un tanto errado.
} 
no apreciados hasta entonces. En efecto, muchas veces los excursus permiten al autor retomar una actitud objetiva después de un pasaje violento en el que él o personajes cercanos se han visto envueltos. ${ }^{15}$

Frente a las afirmaciones de otros autores con relación a la supuesta pretensión desmesurada de conocimiento que presenta Amiano en las digresiones, Sabbah subraya que ellas hacen posible que el historiador adopte una postura de experto en algunas materias, en donde puede exhibir el gusto por la investigación desinteresada, la precisión y la exigencia de verdad. Estas condiciones no las podría mostrar de ningún modo en un relato sobre historia propiamente dicha. ${ }^{16}$

Como hemos visto, las tesis de Mommsen resultaron sumamente perjudiciales para el estudio posterior de los excursus. Paulatinamente, los especialistas comenzaron a interesarse en estas piezas, primero atribuyéndoles un carácter científico y después uno meramente retórico. En la última década la atención se ha centrado casi por completo en las digresiones etnográfico-geográficas. Ya situados en este terreno algunos autores insisten en la necesidad de cambiar el enfoque de las investigaciones, de un análisis de las fuentes y la exactitud de las descripciones geográficas, hacia una comprensión del propósito

${ }^{15}$ Ya a mediados del siglo xx G. B. Pighi creyó que el empleo de digresiones obedecía a cierto orden y que éstas desempeñaban un papel en la estructura general de la obra, casi al mismo nivel de los discursos, cf. Guy Sabbah, La méthode d'Ammien Marcellin, p. 525, n. 51.

${ }^{16}$ G. Sabbah, op. cit. Ma. Luisa Harto Trujillo (Amiano Marcelino, Historia, 2002, pp. 64-66) presenta un concepto de las digresiones que en gran medida refleja el cambio de actitud hacia ellas en el medio académico. Aunque no deja de mencionar la gran cantidad de críticas de parte de los comentaristas hacia los excursus, positivamente recuerda que estas piezas tuvieron la misma importancia para el historiador clásico que el resto de la narración; asímismo insiste en que es necesario tener en mente que las digresiones tenían la única finalidad de agradar y entretener al público, en una época en la que los autores se veían dominados por la erudición y el enciclopedismo. Al final Harto acepta que los excursus poseen total pertinencia en la obra. 
y el método de tales narraciones; ${ }^{17}$ otros rechazan tajantemente la posibilidad de que los excursus constituyan una autoridad en la ciencia geográfica, en cambio subrayan con insistencia su carácter literario. ${ }^{18}$

\section{El excursus etnográfico-geográfico}

\section{A. Generalidades}

La primera digresión de la obra conservada se encuentra al comienzo del libro catorce. ${ }^{19}$ Se trata de un informe acerca de los sarracenos (14.4) - a quienes los antiguos situaban entre los límites de los territorios actuales de Egipto, Israel, Jordania y Arabia Saudita - sus costumbres y sus incursiones en territorio romano. En el mismo libro se encuentra una descripción de las provincias orientales del Imperio (14.8) que tiene como punto de partida el monte Tauro en Cilicia y concluye en las provincias de Arabia y Chipre. El libro quince contiene dos excursus, el primero sobre el territorio alpino - hoy una parte de Suiza, Alemania y Austria - que rodea el lago Constanza o Bodensee (15.4.1-6), en donde se describe poco después una batalla entre Constancio II y los germanos; el segundo es una extensa relación de la región gala (15.9-12), así como del origen y las costumbres de sus habitantes. ${ }^{20}$ En el libro veintiuno se encuentra la descripción del desfiladero del Suco -o Paso

\footnotetext{
${ }^{17}$ Cf. G. Sundwall, op. cit., p. 622.

${ }^{18}$ Cf. J. W. Drijvers, op. cit., passim.

${ }^{19}$ Por referencias del autor se conoce la existencia de otros excursus etnográfico-geográficos sobre Mesopotamia (cf. 14.7.21), Italia (cf. 22.9.6), Britania (cf. 27.8.4), África (cf. 29.5.18), y un segundo sobre Egipto (cf. 22.15.1) y los sarracenos (cf. 14.4.2). Cf. E. Galletier y J. Fontaine, op. cit., p. 29, y supra n. 4.

${ }^{20}$ Hay que hacer hincapié en la oportunidad de estos excursus. Éste por ejemplo sobre la Galia está ubicado adecuadamente entre la designación de Juliano como César y su gestión en aquel territorio. De esa manera, el autor indica a sus lectores que la narración se ha movido a otro punto geográfico y los "familiariza" con él.
} 
Shipka - (21.10.2-4), hoy parte de los territorios búlgaro y griego. $^{21}$

En el libro siguiente tenemos dos digresiones de mayor proporción. La primera sobre Tracia y la región que rodea el Mar Muerto (22.8.1-48) y la segunda sobre la fauna y otras curiosidades de Egipto, sus provincias y ciudades de mayor importancia (22.15-16). En el libro veintitrés se encuentra la relación geográfica de mayor extensión en toda la obra y la que ha despertado mayor interés entre los especialistas. ${ }^{22}$ Se trata de la descripción de Persia (23.6), brillante proemio de las campañas de Juliano en aquella región. Por último, tenemos dos excursus de no menor relevancia. El primero de ellos sobre las provincias de Tracia (27.4), antes de la campaña del emperador Valente contra los godos. El segundo, al final de la obra y antes del relato de la batalla de Adrianópolis, sobre el pueblo de los hunos y los alanos (31.2).

De esta forma es posible establecer que en cuanto a su extensión las digresiones se clasifican en tres grupos. En primer lugar, cuatro grandes excursus sobre extensas áreas geográficas: Persia (23.6), Tracia y el Mar Negro (22.8.1-48), Egipto (22.15-16) y Provincias orientales (14.8). Después, cuatro digresiones de menor proporción: Galia (15.9-12), sarracenos (14.2), hunos y alanos (31.2) y provincias de Tracia (27.4). Por último, dos breves pasajes sobre regiones concretas: lago Constanza (15.4.1-6) y paso del Suco (21.10.2-4).

Para concluir este apartado es oportuno aludir a la naturaleza de cada uno de estos pasajes. Primero tenemos las di-

\footnotetext{
${ }^{21}$ En esta ocasión, como en la descripción del lago Constanza, Amiano define este terreno con la finalidad de crear una atmósfera para su relato del enfrentamiento entre Juliano y tropas de Constancio II.

${ }^{22}$ Cf. M. F. A Brok, “Die Quellen von Ammians Exkurs über Persien”, pp. 4756. Jan W. Drijvers, “Ammianus Marcellinus' Image of Arsaces and Early Parthian History", y Hans Teitler, "Visa vel lecta? Ammianus on Persia and the Persians", en The Late Roman World and its Historian. Interpreting Ammianus Marcellinus, 1999. En español puede consultarse el artículo de Juan Signes, "El excursus de los persas de Amiano Marcelino (XXIII, 6)”, Veleia, VII, 1990, pp. 351-375.
} 
gresiones de carácter específicamente geográfico: Provincias orientales (14.8) y Tracia y el Mar Negro (22.8.1-48). En ellas no hay otra cosa que la descripción de una región determinada, en la que se resaltan las relaciones entre distintos puntos como ciudades, montañas y ríos. ${ }^{23}$ Segundo, las de contenido etnográfico-geográfico: sarracenos (14.2), Galia (15.9-12), Egipto (22.15-16), Persia (23.6), provincias de Tracia (27.4) y hunos y alanos (31.2). Aquí al mismo tiempo que se define el territorio de la región, se presenta un cuadro del origen y las costumbres de sus habitantes, su fauna, y en ocasiones una breve relación de los enfrentamientos entre Roma y aquellos pueblos. Por último, los pasajes que ya se señalaban como de menores proporciones tienen un carácter fundamentalmente topográfico; es decir, aquí se detalla la geografía física de una pequeña región.

\section{B. Estructura y función}

Todos los excursus poseen la habitual fórmula introductoria que los distingue del relato central. Por lo que toca a la fórmula de conclusión (’’ $\left(\varphi \circ \delta \varsigma\right.$ ), sólo dos no cuentan con ella. ${ }^{24}$ Es necesario detenerse en los "prólogos", pues ahí Amiano expone el propósito principal de cada una de las digresiones. Pueden apreciarse tres tópicos principales: la insistencia en la brevedad de los excursus, ${ }^{25}$ el anhelo de exactitud y conoci-

\footnotetext{
${ }^{23}$ Este tipo de descripción se denominó chorographia entre los antiguos.

${ }^{24}$ Lago Constanza (15.4.1-6) y paso del Suco (21.10.2-4). Por lo demás, la

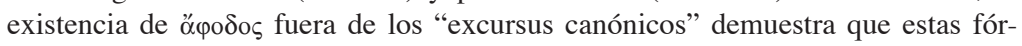
mulas no pertenecen únicamente a las piezas que aquí se estudian (cf. 27.3.15). Deberemos ser muy precisos al momento de establecer las características que distinguen las digresiones etnográfico-geográficas, pues se corre el riesgo de considerar excursus todo pasaje que se "desvíe" del relato, aun cuando posean dichas fórmulas.

${ }^{25}$ Cf. 14.4.2: "pauca de eisdem [de saraceniis] carptim". 22.15.1: "strictim itaque, quoniam tempus videtur hoc flagitare, res Aegyptiacae tangantur". 23.6.1:
} 
miento pleno, ${ }^{26}$ y el tratamiento de una cuestión que entre los antiguos no fue conocida o lo fue muy superficialmente. ${ }^{27}$

La búsqueda de exactitud en la información por parte de Amiano no sólo en las digresiones sino en toda la obra va unida al intento de reforzar la tradición literaria con las propias observaciones. Esto se hace manifiesto en la expresión visa vel lecta quaedam perspicua fide monstrare (22.8.1), con la que el autor da a entender que la fidelidad de los datos que aporta no depende únicamente de las lecturas que ha realizado sino también de aquello que ha visto personalmente. En otras ocasiones, la importancia del conocimiento directo es mayor para Amiano que el de la tradición, la cual muchas veces no es fidedigna. ${ }^{28}$ Esto es patente en una buena cantidad de pasajes en donde se aprecia que la información es de primera mano. El pintoresco cuadro que Amiano nos presenta del poblado de Batna y la feria que ahí se realiza es una muestra de lo que con seguridad él mismo presenció:

Batnae municipium in Anthemusia conditum Macedonum manu priscorum, ab Euphrate flumine brevi spatio disparantur, refer-

"Res adigit huc prolapsa ut in excessu celeri situm monstrare persidis". 27.4.1: "ergo conveniet pauca super harum origine regionum et situ transcurrere per brevem excessum”. Véanse también 15.4.1-6 y 21.10.2-4.

${ }^{26}$ Cf. 22.8.1: "Appositum est... tempus... visa vel lecta quaedam perspicua fide monstrare". 23.6.1: "Res adigit huc prolapsa... situm monstrare persidis. Quod autem erit paulo prolixior textus ad scientiam proficiet plenam".

${ }^{27}$ Cf. 27.4.2: "Erat Thraciarum descriptio facilis, si veteres concinerent stili, quorum obscura varietas quoniam opus veritatem professum non iuvat, sufficient ea, quae vidisse meminimus, expedire". 31.2.1: "hunorum gens monumentis veteribus leviter nota..." 23.6.1: “...persidis, descriptionibus gentium curiose digestis, in quibus aegre vera dixere paucissimi”. Véase asimismo 15.9.2 donde Amiano, a la vez que se queja por las dudas que los antiguos tenían sobre el origen de los galos, elogia la actividad de Timágenes de Alejandría que clarificó el camino en estas cuestiones.

${ }^{28}$ Como es normal existe la idea contraria entre algunos críticos, en especial J. W. Drijvers y G. Sundwall, es decir, la idea de que en Amiano tiene mayor importancia la información proveniente de las fuentes literarias que la de la propia experiencia, cf. supra, n. 8. 
tum mercatoribus opulentis, ubi annua sollemnitate prope Septembris initium mensis, ad nundinas magna promiscuae fortunae convenit multitudo, ad commercanda quae Indi mittunt et Seres, aliaque plurima vehi terra marique consueta. ${ }^{29}$

Resulta muy difícil creer que la información sobre la actividad anual de la feria y la procedencia de los artículos haya sido extraída de alguna fuente escrita. En otra ocasión, al describir las costumbres de los pueblos galos, Amiano nos presenta datos que con toda seguridad recogió a partir del testimonio propio, pues se apartan mucho de aquéllos, en su mayoría loci communes, que atribuye al resto de los pueblos descritos en la obra. Por ejemplo, cuando observa la enorme fuerza del hombre galo, el historiador hace el siguiente comentario:

Celsioris staturae et candidi paene Galli sunt omnes et rutili luminumque torvitate terribiles, avidi iurgiorum et sublatius insolentes. nec enim eorum quemquam adhibita uxore rixantem, multo fortiore et glauca, peregrinorum ferre poterit globus, tum maxime cum illa inflata cervice suffrendens ponderansque niveas ulnas et vastas admixtis calcibus emittere coeperit pugnos ut catapultas tortilibus nervis excussas. ${ }^{30}$

29 14.3.3: "La ciudad de Batne (sic), fundada en Antemusia por los macedonios hace mucho tiempo y a escasa distancia del río Éufrates, rebosa siempre en ricos mercaderes, y todos los años, hacia el inicio de septiembre, acude a ella una gran multitud de gentes de diversa fortuna para la celebración de una feria, en la que se ponen a la venta mercancías enviadas por los indos y los chinos, así como otros productos que suelen transportarse por tierra y por mar". Trad. Harto Trujillo, op. cit., p. 112. Hay que hacer notar que este pasaje se encuentra fuera de los excursus.

30 15.12.1: "Casi todos los galos son de gran estatura, de piel blanca, cabello rojizo, con aspecto terrible por la dureza de su mirada, ávidos de pelea y de un orgullo extremo. Ni siquiera un grupo de extranjeros podría detener a uno de estos galos cuando lucha si se le une su mujer, mucho más fuerte que ellos, de ojos verdes. Y sobre todo cuando una gala, con el cuello hinchado, apretando los dientes y blandiendo sus enormes y níveos brazos, comienza a repartir patadas y puños a la vez, como si fueran proyectiles lanzados por la tensión de las cuerdas". Trad. Harto Trujillo, op. cit., p. 197. 
Amiano subraya con frecuencia que él mismo ha estado en los lugares que describe, por ejemplo en la digresión sobre Persia al discutir la etimología de la palabra "Adiabene":

et veteres quidem hoc arbitrantur. nos autem id dicimus quod in his terris amnes sunt duo perpetui, quos ipsi transivimus. ${ }^{31}$

Por lo demás no hay duda de que las descripciones topográficas del lago Constanza y el paso del Suco son producto de la experiencia personal, a diferencia de las descripciones de las grandes áreas geográficas para las cuales tuvo que recurrir muchas veces a documentos literarios, aun sin negar por completo el conocimiento directo de esos sitios.

La función de los excursus es muy diversa; veamos algunos ejemplos. El excursus sobre las provincias orientales (14.8) de alguna manera "sustenta geográficamente" los acontecimientos que le siguen. ${ }^{32}$ En buena medida este excursus será la referencia para los libros posteriores, pues en innumerables ocasiones Amiano se refiere a las ciudades del oriente y es casi seguro que debió considerar que para el lector era más fácil ubicarse después de haber descrito aquellas regiones. ${ }^{33}$ Aun cuando no puede negarse que toda la pieza es oportuna puesto que el relato sobre oriente está en un capítulo donde los acontecimientos se desarrollan en esa parte del Imperio, no puede dejar de señalarse el hecho de que la introducción de este excursus sea sumamente repentina y artificial. ${ }^{34}$

Se ha subrayado que este excursus, por estar enmarcado por dos episodios muy violentos, tiene la función de relajar la

\footnotetext{
${ }^{31}$ 23.6.21: "Esto es al menos lo que piensan los ancianos (sic. Sería mejor decir "antiguos", pues Amiano alude a la tradición literaria). Pero nosotros pensamos que, en estas tierras, hay dos ríos que fluyen sin cesar y que yo he atravesado personalmente...". Trad. Harto Trujillo, op. cit., p. 530.

${ }^{32}$ G. Sundwall, op. cit., p. 623.

${ }^{33} \mathrm{G}$. Sundwall, ibid.

34 14.7.21: “...obductio capitum, et bonorum ubique multatio versabatur per orientales provincias, quas recensere puto nunc opportunum”.
} 
tensión del relato. ${ }^{35}$ Sabbah observa que la digresión sobre las provincias orientales es un claro ejemplo de combinación entre pasajes "subjetivos" y "tendenciosos" por un lado, y "objetivos" por el otro. Se aprecia cómo un excursus de índole erudita, de relajamiento, está colocado en medio de dos capítulos violentos contra el César Galo. No obstante, el mismo Sabbah deja entrever que sin descartar la primera "hipótesis", el lugar que ocupa el excursus puede deberse también a cuestiones meramente estéticas o a una búsqueda de la variatio en el relato. ${ }^{36}$

El excursus sobre el Lago Constanza (15.4.1-6) es introducido poco antes de que Arbitión, comandante de la caballería de Constancio II, entre en combate en ese lugar con los alemanes. Es como si Amiano quisiera mostrar al lector el terreno donde se enfrentarán los ejércitos, aunque curiosamente durante la narración de los sucesos bélicos ya no vuelve a hacer ninguna referencia a la topografía. Quizá más que por fines prácticos el autor introduzca esta digresión o bien para demostrar que él mismo conoció el lugar, o en su defecto, para exhibir su erudición que sólo a partir de sus lecturas le permitiría esbozar una descripción de la zona.

Como mencionamos, el excursus sobre Galia (15.9-12) se encuentra justo entre la designación de Juliano como César y su actividad pacificadora en aquella provincia. En el aspecto teórico el episodio permite hacerse una buena idea acerca de la función y el lugar que debe ocupar una digresión dentro del relato según Amiano Marcelino. Antes de comenzar propiamente el relato de los hechos de Juliano, Amiano introduce una cita de Virgilio $^{37}$ y a continuación indica que lo apropiado

\footnotetext{
${ }^{35}$ Harto Trujillo, op. cit., p. 132.

${ }^{36}$ G. Sabbah, op. cit., p. 526.

${ }^{37}$ Cf. Harto Trujillo, op. cit., p. 188, n. 47 apunta que Amiano invirtió el orden del verso virgiliano, pues mientras éste se puede encontrar como maior rerum mihi nascitur ordo, maius opus moveo (Aen., VII, 44-45), el historiador escribe maius opus moveo maiorque mihi rerum nascitur ordo (15.9.1). De la misma forma en
} 
es describir la geografía y las características de las Galias (tractus et situm Galliarum). La gran empresa que Amiano tenía ante sí debía realizarse con esmero. Junto a la cita virgiliana, el autor coloca el excursus etnográfico-geográfico. Los dos inauguran la parte medular de la obra. Se puede deducir que el excursus, al menos en las Res Gestae, tiene la función por una parte de enmarcar una narración importante y de situar el terreno donde se sucederán los acontecimientos, de manera que aquélla resulte plenamente inteligible al auditorio o lector; por otra, el excursus enaltece tanto al historiador por sus vastos conocimientos como al relato que anticipa. Poco más adelante en este pasaje Amiano, con una metáfora náutica, nos confirma la razón por la cual una digresión de este tipo debe ir antes de la narración principal:

Galliarum tractus et situm ostendere puto nunc tempestivum, ne inter procinctus ardentes proeliorumque varios casus ignota quibusdam expediens imitari videar desides nauticos, adtrita lintea cum rudentibus, quae licuit parari securius, inter fluctus resarcire coactos et tempestates. ${ }^{38}$

Ésta es la norma para casi todos los excursus etnográfico-geográficos de la obra. Antes de un combate o una serie de sucesos trascendentales Amiano inserta una digressio sobre la región en cuestión. Allí describe la ubicación del terreno, sus condiciones y, en ocasiones, las costumbres, exóticas muchas de ellas, de sus habitantes. La única excepción a la norma - como veremos - la presenta el excursus de Tracia y el Mar Negro

que Virgilio da pie con esta frase al relato de la conquista del Lacio por Eneas, Amiano hace lo propio al emprender la historia de las hazañas de Juliano en la Galia.

38 15.9.1: “...pienso que es apropiado describir ahora la geografía y las características de las Galias, no sea que, al narrar hechos desconocidos para algunos, entre los ardientes combates y los distintos avatares de la guerra, me parezca a esos marineros ociosos que se ven obligados a reparar en medio del oleaje y la tempestad las velas raídas y los cables que podían haber reparado en condiciones más seguras". Harto Trujillo, op. cit., p. 188. 
(22.8.1-48), en donde Amiano se asemeja a aquellos marineros ociosos y debe reparar en medio del oleaje del relato para introducir de forma tardía esta digresión. En efecto, este excursus se introduce de manera extemporánea en el relato. Aunque todavía se encuentra en relación con los hechos de Juliano en Tracia, éstos son narrados ya desde 22.2. Según entiende Guy Sabbah, las embajadas de los pueblos bárbaros a Juliano narradas en 22.7 no tienen una importancia política que justifique una larga exposición sobre la región del Ponto. ${ }^{39}$ Esta vez, a diferencia del plan general de la obra, Amiano relata, en primer lugar, los acontecimientos principales y sólo después de que Juliano se ha trasladado a Antioquía (22.9) registra la digresión sobre el Mar Negro.

El excursus sobre Egipto (22.15-16) comienza en realidad un poco antes (22.14.7), en el momento en que Amiano menciona algunos aspectos del sacrificio al dios Apis. En principio, parece correcto insertar una digresión sobre Egipto en un punto de la narración en que Juliano parece dirigirse a esa región, luego de abandonar Antioquía, en su marcha hacia Persia; sin embargo, no se deduce del relato que Juliano se haya dirigido finalmente a la provincia de Egipto, pues Amiano poco antes de la digresión sólo narra la ascensión del emperador al monte Casio y a continuación algunos hechos en Jerusalén para pasar finalmente a Armenia y Persia. De aquí que el excursus no se ajuste por completo en el texto.

En términos generales, el excursus sobre Persia (23.6) encaja bien en la narración. Juliano ha cruzado el Éufrates y se dispone a entrar en Asiria justo en el momento en que se presenta la digresión en el relato. No obstante, para Sundwall su contenido no está directamente relacionado con los capítulos que la enmarcan, pues allí no habla de las regiones descritas en el excursus. ${ }^{40}$ En cambio para Sabbah esta digresión parece

\footnotetext{
${ }^{39}$ G. Sabbah, op. cit., p. 526, n. 53.

${ }^{40}$ G. Sundwall, op. cit., p. 624.
} 
estar justificada por las necesidades objetivas de la narración. En cuanto las tropas romanas penetran en Asiria es oportuno describir las regiones que a partir de ese momento serán el teatro de los enfrentamientos. ${ }^{41}$ Creemos que es necesario observar que esta digresión más que una simple descripción geográfica constituye una erudita exposición acerca de todos los posibles aspectos del mundo persa a los que un estudioso antiguo podía tener acceso. De entre todas las digresiones etnográfico-geográficas, acaso ésta sobre Persia sea la más elaborada. Lo anterior se hace evidente al advertir que en el excursus se describen provincias que no se ven directamente afectadas por la guerra y que en ocasiones reciben mayor atención que aquellas que sí son marco de los sucesos bélicos. ${ }^{42}$

\section{Contenido}

Amiano Marcelino tiene en consideración ante todo ciudades, pueblos, montañas, ríos, lagos, recursos naturales, fauna y flora. Concede especial importancia a las ciudades. En realidad puede asegurarse que el historiador observa el mundo en términos de ciudades, ${ }^{43}$ aunque también lo hace a través de pueblos o grupos étnicos, en el caso de regiones que carecen de entidades más desarrolladas. Como quiera que sea, Amiano subraya siempre la inexistencia o la abundancia de ciudades en una región determinada. Un buen ejemplo de lo dicho lo

\footnotetext{
${ }^{41}$ G. Sabbah, op. cit., p. 527.

${ }^{42}$ G. Sabbah, op. cit., p. 528, considera que 23.6 es más que un simple relato geográfico por el hecho de que Amiano, según lo expresa en la introducción, quiere rivalizar con sus predecesores que no han establecido la verdad sobre el tema. Amiano se jacta de aportar aquí un "conocimiento científico completo". El crítico francés da a entender que el prólogo a la digresión puede deberse a que Amiano, al saber o suponer las críticas de algunos en contra de Juliano y su campaña persa, desea adoptar su habitual postura de hombre sabio tanto en historia como en geografía, así como su imparcialidad en la campaña.

${ }^{43}$ Como veremos más adelante, esta manera de percibir el mundo determinará en gran medida las descripciones geográficas de las regiones, que tendrán como núcleo los centros urbanos.
} 
proporciona la digresión de las provincias orientales (14.8) en la que se describe parte del Asia Menor, Siria y Palestina. Conforme se establece cada una de las regiones, Amiano se detiene a mencionar las ciudades de mayor importancia, su fundador y en ocasiones su historia reciente. Cuando llega a la descripción de Tarso el autor señala las dos versiones que se conocían acerca de su fundación, ${ }^{44}$ y sobre Mopsuestia relata la historia del fundador, Mopso, tripulante de la nave Argo, quien al extraviarse por accidente fue a morir a las costas de África. ${ }^{45}$ Al llegar a Palestina Amiano recuerda la toma de Jerusalén, la derrota de los judíos en el año 63 a.n.e., así como la formación de la provincia llevada a cabo por Pompeyo. ${ }^{46}$ En otras ocasiones las ciudades son reconocidas por sus recursos naturales. Tal es el caso de Antioquía con la que según el autor ninguna otra ciudad puede competir en abundancia de recursos, ${ }^{47} \mathrm{o}$ de Chipre, la cual con recursos propios puede procurarse la construcción y el equipamiento de barcos sin necesidad de importar ningún material. ${ }^{48}$ Por sobre todas las anteriores, Alejandría es descrita con la mayor minuciosidad. Amiano refiere además de su fundación sus monumentos, su historia, el clima, así como los artistas y pensadores que habitaron en ella. ${ }^{49}$

Los ríos y montañas - como veremos en el siguiente capítulo - son cruciales para la ubicación de una ciudad o una re-

44 14.8.3: "Ciliciam... Tarsus nobilitat, urbs perspicabilis - hanc condidisse Perseus memoratur, Iovis filius et Danaes, vel certe ex Aethiopia profectus Sandan quidam nomine vir opulentus et nobilis".

45 Ibid.: "Mobsuestia, vatis illius domicilium Mobsi, quem a commilitio Argonautarum, cum aureo vellere direpto redirent, errore abstractum, delatumque ad Africae litus, mors repentina consumpsit..."

46 14.8.12: "has... regiones pari sorte Pompeius Iudeis domitis et Hierosolymis captis, in provinciae speciem delata iuris dictione formavit".

47 14.8.8: "hanc [Syriam] nobilitat Antiochia, mundo cognita civitas, cui non certaverit alia advecticiis ita adfluere copiis et internis". En otro pasaje Amiano como buen antioqueno llama a su ciudad "Orientis apicem pulchrum" (22.9.14).

48 14.8.14: "Tanta autem tamque multiplici fertilitate abundat rerum omnium eadem Cyprus, ut nullius externi indigens adminiculi..."

49 22.16.7: "Alexandria, vertex omnium civitatum". 
gión. Amiano se detiene a señalar en ocasiones sus características y sus beneficios para los pobladores cercanos. Quizá el río que recibe mayor atención de parte del historiador sea el Nilo $;^{50}$ de él se mencionan su probable fuente, el curso que sigue, su desembocadura y los beneficios o perjuicios que trae según suba o baje de nivel más de lo que conviene. También otros ríos importantes y famosos en la antigüedad son mencionados por Amiano dando una muestra al lector de sus conocimientos "universales". ${ }^{51}$ Otro tanto puede decirse de las montañas. Amiano refiere elevaciones célebres como el Tauro, el Casio y el Atos. Asimismo, el historiador presta especial atención a las montañas de la Europa occidental como los Apeninos, los Pirineos - que ya menciona César- y los Alpes Cocios (Alpes Cottiennes), a los cuales incluso dedica todo un capítulo en su informe de la Galia. La vida animal y vegetal no recibe mucha atención en el interior de los excursus etnográfico-geográficos. El pasaje más importante es sobre la fauna egipcia (22.15.15-27). Allí Amiano especifica las características de cocodrilos, hipopótamos, aves y serpientes. Plantas y algunos frutos son mencionados en la digresión de Persia (23.6.16), así como en el episodio "técnico" sobre las palmeras (24.3.12-13).

\section{Excursus sobre la tradición etnográfica}

Hagamos a continuación un breve paréntesis sobre los orígenes de la tradición a la que Amiano pertenece. En los periplos y en las "genealogías" antiguas fue donde primero se incluyeron las

\footnotetext{
50 22.15.3: "Pauca itaque super benivolo omnium flumine Nilo..."

${ }^{51}$ Entre muchos otros Amiano menciona el Cydno, en Cilicia, el Éufrates, el Orontes (14.8); el Rin (la descripción de su curso se hace en 15.4.1-6), el Garona, el Sena, el Ródano (Amiano se detiene a describir su curso 15.9-12); el Hebro, los ríos de Escitia (Tanais, Boristenes, Halys, Danubio-22.8.1-48); el Ganges (23.6.13), el Tigris y los ríos persas (23.6).
} 
narraciones sobre las costumbres y el carácter de los pueblos, producto de los informes de viajeros. ${ }^{52}$ Poco después Hecateo, y sobre todo Heródoto, lograron sintetizar y organizar el material que hasta ese momento estaba disponible, añadiéndolo a sus propias investigaciones. La época helenística también contribuyó con documentación original acerca de los distintos pueblos que limitaban con los griegos. Las conquistas de Alejandro permitieron realizar investigaciones sobre las civilizaciones más lejanas. Se revaloró la información etnográfica contenida en los poemas homéricos. Todo ello propició la creación de un "canon" de autores que sería la base de la tradición etnográfica en los siglos siguientes. A Homero y a los autores mencionados se añadieron las figuras de Teopompo y Posidonio, los cuales no sólo proporcionaron valiosa documentación a las obras posteriores griegas y latinas sobre las costumbres de los pueblos, sino también un "cuadro" o "esquema" dentro del cual debía colocarse dicha documentación. De esa manera todo aquel que deseara dedicarse al estudio de la etnografía, sin importar el género literario al que perteneciera su obra, contaba con reglas formales fijas, así como con un lenguaje técnico. ${ }^{53}$ Específicamente en el terreno de la historiografía eran, en general, cinco las cuestiones a considerar en la descripción de una región dentro de un excursus:

1. La geografía física (situs).

2. Origen y características de los habitantes (gentes).

3. Clima.

4. Recursos naturales, productos agrícolas, etc.

5. Organización política, social y militar.

Aunque no existe un orden específico en el tratamiento de los puntos anteriores, es común que situs preceda a gentes. De

\footnotetext{
${ }^{52}$ Cf. infra, pp. 282-284 y 288 ss.

${ }^{53}$ Aquí es necesario distinguir entre "tratados técnicos" como los de Estrabón o Plinio y los "ensayos literarios", como la Germania o los excursus etnográficogeográficos que aquí se analizan.
} 
cualquier modo, al menos brevemente, todos debían ser tratados. Era normal que los autores incorporaran un grupo de "curiosidades convencionales" acerca de la región descrita (la característica propia de un mar o suelo determinado, etc.). Entre estos elementos constituyen un cúmulo de loci communes los que se refieren a las características físicas y las costumbres de los pueblos: los bárbaros son altos, robustos, de mirada fiera; no practican la agricultura y no tienen un hogar estable; no tienen leyes, ni una sólida organización política. A pesar de ello, en ocasiones el historiador también aporta datos geográficos y etnográficos originales, producto de su propia observación o de otros testigos. ${ }^{54}$

En el plano teórico los excursus etnográfico-geográficos reflejan muchas de los pensamientos predominantes en torno a la visión que se tenía del mundo no greco-romano. Una de las ideas más recurrentes es la que se refiere a la relación que guarda la manera de ser de los pueblos con el medio en el que se desenvuelven. Según esta teoría, los rasgos físicos y el aspecto psicológico de los pueblos reflejan las particularidades del suelo. En este sentido, el papel de Posidonio de Apamea fue trascendental. Se cree que él fue el primero dentro de la escuela estoica que, por un lado, descuidó el estudio de la ética y, por otro, dirigió todos sus esfuerzos al cultivo de las ciencias. Entre ellas concedió gran importancia a la historia. ${ }^{55}$ En este campo Posidonio se distancia también de la visión predominante, pues además de interesarse por la historia militar y política como había sido a partir de Tucídides, pero sobre todo de Polibio, consideró para el relato histórico los aspectos

\footnotetext{
${ }^{54}$ En la Vita Agricolae, Tácito introduce algunas cuestiones como la forma de Escocia $(X, 3)$ y la insularidad de Britania $(X, 4)$ que muy probablemente fueron producto de su propia experiencia o de la de algunos navegantes. Cf. Cornelii Taciti, De Vita Agricolae, p. 165. Ya tendremos oportunidad de ver la información que, al menos en apariencia, aporta Amiano Marcelino de manera original. Cf. además supra, pp. 269 y ss.

${ }^{55}$ Laistner, M. L. W., The Greater Roman Historians, p. 18.
} 
económicos, sociales, culturales, etnográficos, geográficos, religiosos y los relativos a las ciencias naturales. Su idea de la historia estaba influida por la concepción estoica de la naturaleza, a partir de la cual debían considerarse todos los elementos históricos activos como partes de un todo.

Posidonio contribuyó de manera importante en el campo de la etnografía. Pensaba que esta ciencia tenía la función de revelar el carácter y la psicología de los pueblos. Creía que la etnografía constituía una manera de comprender sus costumbres y tradiciones más arraigadas. En suma, era una forma de explicación histórica. Esta teoría influyó sobre la totalidad de la literatura etnográfica en los siglos siguientes. ${ }^{56}$ Otra teoría importante, manifiesta entre otras obras en la Germania, se refiere a la pureza del "estado de naturaleza" y a la corrupción que significa la civilización y el progreso. ${ }^{57}$ Tácito valora las tradiciones primitivas de los germanos entre las que se cuentan el rechazo a los metales preciosos, su desconocimiento de la usura y los lujos funerarios. Estas características del "estado natural" hicieron que muchos etnógrafos antiguos vieran una supuesta superioridad allí donde otros veían claros ejemplos de barbarie. De cualquier forma, la idealización de los pueblos bárbaros se convirtió en una norma dentro de la etnografía.

\footnotetext{
${ }^{56} \mathrm{Al}$ parecer, esta teoría había sido enunciada por primera vez en el siglo v a.n.e.

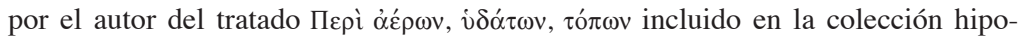
crática. Más tarde Posidonio, que atribuyó a los distintos climas ciertas aptitudes intelectuales y morales, así como determinados regímenes políticos, se encargó de rescatarla para el mundo romano. Para otras referencias, véase Cic., de fato, 7; Curt., VIII, 9, 20; Tac., Agr., XI, 2, y Vitr., VI, 1. Cf. Tacite, La Germanie, p. 16, n. 2.

${ }^{57}$ Esta idea tiene su origen entre los sofistas, quienes rescataron las concepciones en torno a la edad de oro, pero fueron sobre todo los cínicos y los estoicos quienes contribuyeron a fortalecer la tesis. Por lo demás a partir de Éforo comenzó la idealización de los pueblos bárbaros como hombres inocentes y, por ello, fuera de los vicios de la civilización. Cf. Jaques Perret, op. cit., p. 17.
} 


\section{La etnografía en las Res Gestae}

Del material contenido en los excursus etnográfico-geográficos suscitan gran interés los "estudios etnográficos" de Amiano Marcelino sobre los pueblos bárbaros. En términos generales, puede decirse que todos ellos se reducen a una descripción de su vida y sus costumbres. Amiano Marcelino, quien deseaba situarse en la línea de la historiografía clásica, se ve obligado a incluir información sobre los pueblos situados fuera de la esfera greco-romana. Este recurso iba dirigido sobre todo al público romano, que debió disfrutar las descripciones de las costumbres, a sus ojos muchas veces exóticas, de aquellas naciones. Por otro lado, junto a su función retórica, los excursus con contenido etnográfico también deben considerarse dentro del contexto en el que se escribió la obra, es decir, la época en la que bárbaros de distinta procedencia presionaban sobre las fronteras del Imperio.

Amiano incluye diversos topoi que pueden aplicarse a casi todos los pueblos por igual. Por ejemplo los sarracenos, hunos y alanos no trabajan la tierra, carecen de viviendas y leyes, por lo tanto andan errantes la mayor parte de su vida. Su alimentación es la carne, leche y hierbas salvajes. ${ }^{58}$ En lo que respecta al origen de los bárbaros - la etnología propiamente, un elemento indispensable en los excursus etnográficos-, Amiano sólo lo discute en dos ocasiones, cuando habla de los persas y los galos. ${ }^{59} \mathrm{El}$ aspecto del clima está prácticamente ausente de sus informes. Por el contrario, el historiador describe con de-

\footnotetext{
${ }^{58}$ La formulación de Amiano es de mejor factura, 31.2.3: "insuavi ita visi sunt asperi, ut neque igni neque saporatis indigeant cibis sed radicibus herbarum agrestium et semicruda cuiusvis pecoris carne vescantur".

${ }^{59}$ En el caso de los sarracenos quizá debió de tocar ese punto en el primer excursus, pero por desgracia no logró conservarse. Recordemos que Amiano no menciona el origen de los hunos y alanos, quizá por no haber sido un tema discutido en la antigüedad, como él mismo lo señala.
} 
tenimiento los rasgos físicos. Los hunos son de cuerpo robusto y firme, los alanos rubios, altos y de brazos largos, los persas delgados y morenos y los galos también de gran estatura, piel blanca y cabello rojo. ${ }^{60}$

Es común que Amiano no refiera los recursos naturales de las regiones bárbaras o la organización política y social de sus pueblos, puesto que para él eran hombres nómadas y que, por lo tanto, no aprovechaban permanentemente las riquezas que les ofrecía un lugar determinado. Asimismo su volubilidad y falta de organización les impedía poder establecer alguna forma de gobierno o sociedad. ${ }^{61}$

Por último, Amiano incluye en sus informes algunas descripciones que de inmediato resaltan por su rareza. Se trata en unos casos de lugares comunes atestiguados en la literatura etnográfica y en otros de relaciones extraídas quizá de la experiencia personal. Así, los sarracenos se entregan al amor con un ardor muy peculiar, ${ }^{62}$ desconocen el vino y el trigo - según la comprobación personal del historiador-, aunque los galos están ávidos de él (genus avidum vini). Los hunos emplean como vestido telas de lino, pieles de ratón y de cabra para las piernas, y no se quitan la túnica sino hasta que se les cae de vieja. Los alimentos los comen crudos y, en todo caso, suelen calentarlos entre sus piernas y el lomo de los caballos. También este pueblo tiene la costumbre de cubrir las mejillas de los niños con metal, de esa manera envejecen sin barba y sin belleza alguna. Por su parte, los alanos acostumbran, después de asesinar al enemigo, degollarlo y colocar su cuero

\footnotetext{
${ }^{60}$ Es curioso el rasgo común que Amiano ve en alanos, persas y galos: la mirada amenazadora. Los alanos son oculorum temperata torvitate terribiles, los persas caprinis oculis torvi y los galos luminum torvitate terribiles.

${ }^{61}$ Todos los pueblos comparten el carácter guerrero y cruel, pero Amiano muestra especial animadversión hacia los hunos: son desleales y volubles en los acuerdos, no respetan la religión, están ávidos de lo ajeno y no distinguen entre lo honesto y lo deshonesto.

62 14.4.4: "incredibile est quo ardore apud eos in venerem uterque solvitur sexus".
} 
cabelludo sobre su caballo como insignia de victoria; no tienen templos ni lugares sagrados, poseen formas extrañas de predecir el futuro, y su divinidad es la espada. Por último, las mujeres galas son más fuertes y agresivas que el hombre. ${ }^{63}$ Como puede verse, el contenido de los excursus es muy variado. Esto demuestra que el aspecto etnográfico aunque es un elemento imprescindible dentro de la historiografía antigua, y existieron normas para su elaboración, no estuvo claramente definido en la antigüedad.

\section{Aproximaciónal estudio de la orientación espacial en el excur- sus etnográfico-geográfico de la historiografía greco-romana}

\section{A. Generalidades}

El debate en torno al uso de mapas en el mundo antiguo ha cobrado mayor fuerza en algunos círculos académicos en los últimos veinte años. En general, existen dos tendencias con relación a esta cuestión. La primera, defendida principalmente por O. A. W. Dilke, ${ }^{64}$ considera que los antiguos emplearon mapas de forma muy similar al modo como se les utiliza actualmente. Por otra parte, algunos investigadores como Richard Talbert niegan que su uso haya sido frecuente en la antigüedad grecolatina. ${ }^{65}$ Lejos de enfrascarse en una polémica quizá infructuosa, los defensores de esta última posición han ampliado sus miras y debido a la escasez de documentos que atestigüen la supuesta difusión del mapa en Grecia y Roma prefieren abordar el problema desde el punto de vista de la geografía conceptual. De esta manera han llegado al punto de formular-

\footnotetext{
${ }^{63}$ Sobre este curioso pasaje, cf. supra, p. 271, n. 30.

${ }^{64}$ O. A. W. Dilke, Greek and Roman Maps, 1985.

${ }^{65}$ R. Talbert, "Rome's Empire and Beyond: The Spatial Aspect", 1988. Un bosquejo de esta polémica puede encontrase en Mary E. Downs, "Spatial Conception in the Ancient Geographers", p. 46, n. 2, y Gavin A. Sundwall, op. cit., p. 619, n. 2.
} 
se interrogantes de gran importancia en torno a la relación que guardan los mapas, pero sobre todo las narraciones geográficas antiguas, con la representación del espacio geográfico. Al abordar el problema partiendo del análisis de las descripciones verbales de geógrafos e historiadores, surgen preguntas acerca de la manera como concebían los antiguos el espacio que estructuran de forma narrativa y la forma en que el auditorio o lector podía seguir tales descripciones, que en algunos casos intentaban reproducir lejanas y vastas regiones y que - podemos asegurar - a un lector de nuestros días le resultan confusas y poco fidedignas. Al final, como argumenta Mary E. Downs, lo que se pretende no es señalar las limitaciones de las percepciones antiguas acerca del espacio geográfico, sino tratar de reconstruir la idea que se tenía del mundo y que hizo posible la creación de mapas y narraciones geográficas autorizadas. ${ }^{66}$

Sigamos un poco los argumentos de la estudiosa con respecto a este asunto. En primer lugar, Downs se decide por la teoría que descarta el uso extendido de mapas entre los antiguos. Asegura que una prueba de ello es la existencia de múltiples descripciones geográficas en la literatura griega y latina; en cambio, hay pocos mapas conocidos actualmente provenientes de la antigüedad. Pero si los mapas no eran de uso corriente, entonces ¿cómo se formaron, sobre todo los geógrafos, una noción del espacio? Y ¿cómo recibía dicha noción el auditorio al que iban dirigidos los relatos que la contenían? Para poder comprender la noción espacial antigua es necesario - continúa Downs - interpretarla de acuerdo con las convenciones que estuvieron vigentes entre los geógrafos y el común de las personas. Para Bekker-Nielsen la visión romana de la geografía es "subjetiva", quiere decir esto que la percepción del espacio que los antiguos tuvieron fue predominantemente "lineal". 67

${ }^{66}$ Mary E. Downs, op. cit., p. 37.

${ }^{67}$ T. Bekker-Nielsen, Terra Incognita: The Subjective Geography of the Roman Empire, 1988, citado por M. Downs, op. cit., p. 37. Los geógrafos conceptuales 
Tanto los mapas como las descripciones de geógrafos e historiadores son ejemplo en un gran número de ocasiones de los mapas mentales de tipo "lineal". Tal es el caso de los Itineraria, como la Tabula Peutingeriana, el único itinerario conservado en forma gráfica. ${ }^{68}$ Este mapa, aunque en apariencia confuso a ojos modernos y cuyas descripciones son en general poco exactas, refleja el mapa mental "lineal" tanto del autor como de los destinatarios. Por otra parte, los autores de relaciones geográficas casi sin excepción se mueven en sus descripciones linealmente, "de un punto a otro", muy probablemente influidos por la estructura establecida por los itinerarios y mapas de viaje: puede ser a lo largo de un río, un camino o algún límite determinado, pero nunca se apartan de él. ${ }^{69}$ Los

distinguen entre "mapas lineales" (strip maps) y "mapas abiertos o de área" (broad maps). El primer tipo, como su nombre lo dice, une los puntos en el espacio a través de una relación rectilínea y el segundo a través de una relación de área como los mapas actuales. No hay testimonio de la existencia de este último tipo en la antigüedad. Más aún, Richard Talbert, op. cit., p. 216, afirma que los únicos mapas de uso más o menos común fueron los mapas lineales.

${ }^{68}$ Las principales fuentes de los geógrafos son los Itineraria y los periplos. Los Itineraria tenían la función de proporcionar a los viajeros los nombres de una serie de lugares por los cuales se podía pasar, así como la distancia existente entre ellos. Algunos de los itinerarios más conocidos a parte de la Peutingeriana son: Itinerarium de Antonino, Itinerarium Alexandri, Itinerarium Burdigalense, la Notitia Dignitatum, y de época posterior, la Peregrinatio ad loca sancta y los Itinera Hierosolymitana. Cf. Dilke, op. cit., pp. 112-129, y Sundwall, op. cit., p. 620.

${ }^{69}$ Los itinerarios proporcionaban distancias "exactas" entre los distintos puntos de una ruta determinada. En este sentido es casi seguro que Amiano empleó itinerarios, puesto que en varias ocasiones menciona la distancia existente entre ciudades o la extensión de algún lago o mar - quizá extraída de alguna periégesis-. No obstante, Sundwall, op. cit., 632, n. 33, opina que Amiano, si bien utilizó tales fuentes en muchas ocasiones éstas no contenían distancias "exactas", y por ende el historiador no siempre las tiene en cuenta. Si es verdad que las ideas geográficas fueron concebidas a partir de los Itineraria, entonces cabe pensar que la sucesión de poblados, ciudades y otros puntos de referencia dentro de los itinerarios era más importante que la distancia que había entre ellos. Como ejemplo de esto podemos mencionar el caso de la Germania. Allí Tácito estructura su relato de acuerdo con la célebre "ruta del ámbar", o el caso de la digresión sobre Tracia y el Mar Negro donde, según J.W. Drijvers, op. cit., Amiano se basó en los periplos existentes de esa región. 
problemas surgen cuando lo que se describe es un elemento situado en un área extensa, como una cordillera que no posee un punto de demarcación fijo o que no está en referencia a un camino o a una costa. También surgen conflictos en la delimitación de regiones o grupos étnicos. En todos estos casos el lector moderno no es capaz de seguir fielmente el relato.

Volviendo al término "mapa mental", hay que indicar que es producto del almacenamiento y de la memorización, a través de sucesivos viajes, de información necesaria sobre un espacio determinado. Refleja el mundo tal y como se le percibe y no necesariamente como es en realidad. ${ }^{70}$ Con seguridad los antiguos creían que sus descripciones geográficas proporcionaban la ubicación "exacta" de los grupos humanos; pero para evitar caer en problemas de "exactitudes", hay que decir que deseaban principalmente resaltar la riqueza y la grandeza del Imperio Romano, el único que había sido capaz de conquistar pueblos tan diversos. Aquí es necesario tomar en cuenta factores ajenos a los meramente técnicos y científicos. En la creación de un informe geográfico también entraban en juego las propias intenciones del autor, las fuentes a su disposición y sus recursos cartográficos o en el caso de los historiadores los vocablos empleados en la descripción.

Como quiera que sea, nos interesa en estas líneas enfocarnos en los términos que el historiador utiliza para representarse el espacio. Fundamentalmente son todas aquellas expresiones que indican distancia, dirección y puntos de referencia. Son sus herramientas en la orientación espacial. Por lo tanto, junto a la descripción del mundo físico (ríos, montañas, flora, fauna, etc.) hay que tener en consideración el aspecto espacial en el análisis del excursus etnográfico-geográfico dentro de la historiografía antigua.

\footnotetext{
${ }^{70}$ M. Downs, op. cit., p. 43.
} 


\section{Antecedentes del excursus etnográfico-geográfico: historiografía griega (Heródoto)}

En la antigüedad se desarrollaron tres líneas de investigación geográfica: ${ }^{71}$ la primera de ellas es la que aparece en los es-

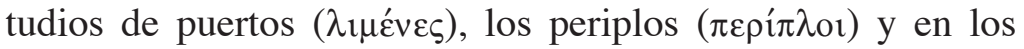

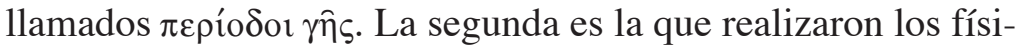
cos y los matemáticos. ${ }^{72}$ La tercera es la que se encuentra en las obras históricas a manera de "secciones" sobre topografía; es decir, los excursus. ${ }^{73}$ Cronológicamente los periplos son los más antiguos dentro de esta clasificación. Tienen su origen alrededor del siglo vi a.n.e. ${ }^{74}$ En términos generales los periplos eran descripciones de las costas de una región determinada. Su método consistía en resaltar los puntos más importantes en la circunnavegación de un territorio, como ciudades, ríos y montañas. Ocasionalmente se incluía la distancia existente entre dos lugares así como alguna información relativa a las características físicas del terreno. Como descendientes de los relatos de viaje arcaicos, primero en forma oral y luego en prosa, los periplos en principio tenían una finalidad práctica. ${ }^{75}$

Se buscaba tener una noción de los pueblos más remotos, sobre todo para poder comerciar con ellos, o bien dominarlos

\footnotetext{
${ }^{71}$ Quizá el primero en advertir este desarrollo de la geografía haya sido Estrabón (cf. VIII, 1, 1), aunque también es probable que haya tomado esta idea de Posidonio.

${ }^{72}$ Como Posidonio e Hiparco, según Estrabón.

${ }^{73}$ Estrabón menciona como ejemplos de este tipo de investigación a Éforo y Polibio.

${ }^{74}$ Los periplos más antiguos de los que se tiene noticia son el de Escílax de Carianda sobre los dominios persas y aquél, posiblemente obra de un griego de Marsella, que sirvió como fuente primero a Éforo y finalmente a Avieno para su Ora Maritima del siglo IV d.n.e.

${ }^{75}$ La vieja autopsia jonia, que hará posible el surgimiento de la historia, es la base teórica para los relatos de viaje con fines prácticos y luego para los de tipo "histórico".
} 
militarmente. ${ }^{76}$ Junto a los periplos (las descripciones de la tierra y puertos son de elaboración posterior) existían otro tipo de relatos como las crónicas de ciudades y pueblos y las "genealogías". Estas últimas contenían datos etnográficos, curiosidades, tradiciones míticas y en algunas ocasiones no carecían de información propiamente geográfica. Las genealogías añadieron a la finalidad práctica que tenían los periplos el valor y la utilidad que la información sobre el espacio y la historia de otros pueblos podría proporcionar al conocimiento de aquellos que las escribían y de su ámbito intelectual y político.

Este conjunto de relatos recibieron el nombre de $\lambda$ ó yor y a diferencia de los cantos épicos estaban escritos en prosa. A pesar de ello, los $\lambda$ ó $\gamma o r$ eran en el fondo una continuación de la épica, pues seguían el esquema trazado por aquélla en lo que a la presentación de la historia de los pueblos y las ciudades se refiere. Del mismo modo en que la épica lo había hecho con la "historia mítica", los $\lambda$ ó yor lo hacían con la "época histórica", sólo que con un método y un propósito distintos.

El desarrollo de los relatos geográficos derivó inevitablemente en un interés más allá del meramente práctico. El saber que podían aportar estas narraciones se concibió como un elemento imprescindible para comprender los hechos históricos. Esta nueva actitud es patente a partir de la obra de Heródoto. El historiador tiene la necesidad de situar en el espacio su narración, así como proporcionar informes sobre todos los aspectos posibles de los pueblos tratados en el relato. De ahí la adición de relaciones geográficas y etnográficas. No obstante, en Heródoto el elemento geográfico y el histórico aún aparecen íntimamente unidos, la cantidad de datos de uno y otro campo presentados en la obra es similar. Posteriormente es tal el volumen de información recabada que se torna

\footnotetext{
${ }^{76}$ Recuérdese los relatos de viaje que menciona Heródoto como la célebre circunnavegación de los fenicios por África y el Atlántico norte (cf. IV, 42).
} 
complicado incluir todo en un solo tratado. Los autores se ven obligados a decidir por uno o por otro terreno. Así, a partir de la línea que sigan, se funda el género historiográfico y la parte geográfica se ve reducida o surge la "geografía científica" y el relato literario de viajes, y la historia pierde peso. El relato de viajes como género y la geografía científica de Hiparco, Eratóstenes y Eudoxo tuvieron un desarrollo totalmente distinto a la historiografía, y en el caso de la geografía científica mucho más fecundo que los dos restantes. Pero como su historia y sus objetivos se alejan demasiado de los propósitos de estas líneas, enfoquémonos en la geografía dentro del género histórico.

Decíamos que lo primero fueron los relatos de viaje. Con los avances de la ciencia jonia y el nacimiento de la i $\sigma \tau$ opí $\alpha$, los escritores profundizaron en las relaciones que proporcionaban aquellas antiguas narraciones. A partir de este momento las investigaciones ya no se proponían únicamente hacer una enumeración de determinados puntos en el espacio, sino que, con la nueva información obtenida, se pretendía contribuir con un conocimiento más fidedigno sobre pueblos y países. Representó un avance en este sentido la obra de Hecateo de Mileto. A este autor se le atribuyen unas Genealogías y un par de libros de Periégesis o viaje alrededor del mundo. Aunque al parecer la obra de Hecateo tiene todavía muchas características propias del periplo, se cree que fue de una mejor manufactura que todo lo escrito hasta ese momento. Su relato exhibe rasgos que serán representativos de las narraciones geográficas posteriores, como las historias mitológicas, descripción de animales y relaciones sobre las costumbres de los pueblos.

Con todos estos antecedentes, surge la obra de Heródoto de Halicarnaso. Como se dijo, en las Historias todavía aparecen entremezclados los datos geográficos e históricos. Se advierte una indefinición acerca del área que debe sobresalir en el relato. Es como si la vieja tradición de los $\lambda$ ó

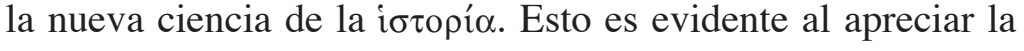


estructura general de la obra. Hasta su primera mitad el relato histórico se supedita a la exposición de los $\lambda$ ó you, lo fundamental es ésta, sólo a partir del libro $\mathrm{V}$ el papel preponderante lo tendrá aquél. Los libros segundo y cuarto constituyen auténticos $\lambda$ ó oı sobre Egipto y Escitia, que, a pesar de no carecer de información histórica, privilegian el aspecto geográfico y etnográfico. Algo similar se puede afirmar por lo que respecta al libro primero, el cual incluye extensas relaciones sobre Lidia y Persia. ${ }^{77}$ En la segunda parte de la obra también se encuentran $\lambda$ ó Tracia en el libro quinto y a Esparta en el sexto.

De cualquier modo, sea que el relato esté dominado por los $\lambda$ ó nográficas ocupan un lugar primordial dentro del esquema de la obra, primero como componentes de los grandes $\lambda$ ó ${ }^{\circ}{ }^{78}{ }^{78}$ y luego a través de breve información que se intercala en la narración. ${ }^{79}$ No siempre Heródoto está en condiciones de presentar un cuadro completo de las costumbres y la historia de cada pueblo que su relato registra; no obstante, tiene la necesidad en todos los casos de establecer en sucintos párrafos la posición geográfica y de mencionar las costumbres de las

\footnotetext{
${ }^{77}$ Esta composición ha llevado a suponer que Heródoto consideró la posibilidad

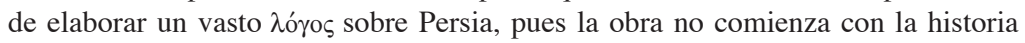
griega ni es ésta su núcleo, como podría ser natural para un escritor griego, sino que a partir de la historia oriental se inserta la historia de Grecia.

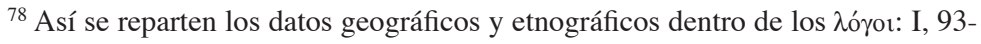
94 Costumbres de los lidios; I, 131-140 Costumbres de los persas; II, 5-34 Geografía de Egipto; II, 35-98 Costumbres de los egipcios; IV, 16-35 y 47-82 Geografía y etnografía de Escitia; V, 3-10 Costumbres y geografía de los tracios.

${ }^{79}$ Con la diversidad de pareceres de los editores así se distribuyen los datos geográficos y etnográficos por medio de excursus: I, 171-173 Origen y costumbres de carios, caunios y licios; I, 178-191 Descripción e historia de Babilonia; I, 192-200 Territorio y costumbres de los babilonios; I, 201-204 Posición geográfica de los masagetas; I, 215-216 Costumbres de los masagetas; III, 90-117 Excursus geopolítico del imperio persa (III, 98.2-102 Sobre la India); V, 49-54 Descripción de los países entre Sardes y Susa; VII, 198-201 Topografía de las Termópilas; VIII, 71-73 Etnografía del Peloponeso.
} 
naciones. En otras ocasiones describe las características físicas de una región determinada donde a continuación se suscitará una batalla. Estas "intromisiones etno-geográficas" fuera de los $\lambda$ ó yor tendrán un lugar importante dentro de la historiografía hasta el final de la antigüedad. Lo más probable es que Heródoto no haya sido el creador del excursus como lo demuestran las palabras de Quintiliano, quien ya veía en Homero la semilla de la digressus, ${ }^{80}$ pero en todo caso la tradición del excursus etnográfico-geográfico parte del historiador jonio. Digamos desde ahora que el excursus geográfico tal y como se presenta en la literatura latina, si bien tiene en Heródoto su inicio, aún se necesitarán algunos siglos para que llegue a establecerse como un elemento con reglas fijas y con información tomada de la tradición más que de la propia experiencia del historiador.

Es común que el excursus se presente en las Historias de forma inesperada; es decir, que no existe indicación alguna que lo anteceda. De la misma forma, no es propio del historiador marcar de nuevo la transición hacia el relato central por

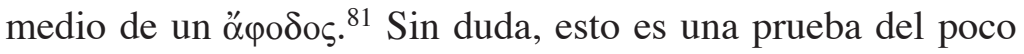

\footnotetext{
${ }^{80}$ No obstante, parece que es Heródoto el primero en registrar el término "digresión", así como el primero que se propuso incluir digresiones en su relato (cf. IV,

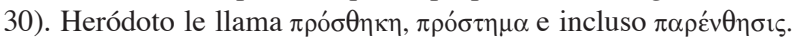

${ }^{81}$ Son pocas las indicaciones para retomar el curso del relato. Por ejemplo Heródoto coloca un ǒ́podoৎ al término de la exposición de las costumbres de los per-

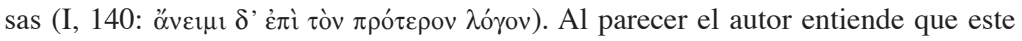
episodio es distinto al relato de la historia de Persia. Para Carlos Schrader, Heródoto, Historias, p. 55, esta fórmula puede retomar lo dicho en el párrafo 95, aunque es poco probable que Heródoto considerara toda su relación de Persia como una pieza añadida entre la historia de Lidia y la narración de los enfrentamientos entre los griegos de Asia y la propia Persia que inicia en el párrafo 141. Heródoto coloca otra marca al término de la relación etnográfica de los escitas (IV, 82: $\dot{\alpha} v \alpha \beta \eta ́ \sigma o \mu \alpha \imath$

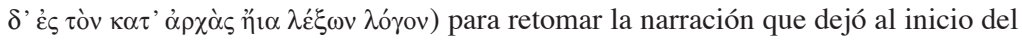
libro IV sobre la causa de la expedición de Darío contra ese pueblo. Según W. W. How y J. Wells, A Commentary on Herodotus, p. 323, en algunos casos la partícula

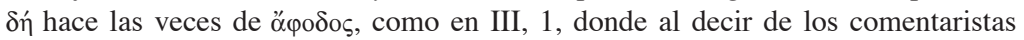
dicha partícula pretende retomar el hilo de la narración de II, 1. Ello indica que para How y Wells toda la relación sobre Egipto - es decir el libro II - debe de ser
} 
desarrollo que tiene el excursus como pieza literaria en esta época, además de que la ausencia de marcas que lo delimiten no permite establecer con exactitud la extensión ni la estructura general de cada uno de ellos.

En cuanto al contenido, Heródoto acostumbra registrar descripción de ciudades y sus enormes construcciones, ${ }^{82}$ establecer el terreno de una región determinada y mencionar a sus moradores, ${ }^{83}$ definir una vasta zona geográfica ${ }^{84}$ e incluir la fauna. El historiador tiene el mérito de reconocer la importancia de la descripción de países para la historia. Por el contrario, se le ha criticado el hecho de que los datos geográficos estén subordinados al tema principal y que trate a la ciencia geográfica desde un punto de vista meramente empírico. Además revela un profundo desconocimiento de la teoría científica como la relativa a la temperatura de las regiones, fertilidad de suelos y presión atmosférica ( $j$ sic!). ${ }^{85}$ En cambio, rasgo sobresaliente -y que habrá de tener enorme resonancia entre los historiadores posteriores - es la inclusión de sucesos mitológicos entre las descripciones geográficas. Por último, creemos que ya para Heródoto es crucial establecer relaciones entre los distintos elementos - ríos, montañas, ciudades y pueblos - que conforman el terreno geográfico para ubicar al lector en el espacio donde se localiza el relato. Intentaremos probarlo.

entendida como un excursus. Como ya vimos esto no es necesario pues aunque en rigor el informe etnográfico interrumpe la narración de la serie de ofensivas persas contra los pueblos vecinos, la estructura obedece en esta obra a la tradición que marcaron los $\lambda$ ó ${ }^{\circ}$, de donde surge el excursus.

${ }^{82}$ I, 178-191: Descripción e historia de Babilonia.

${ }^{83}$ VII, 198-201: Topografía de las Termópilas y VIII, 71-73: Etnografía del Peloponeso.

${ }^{84}$ IV, 37-45: Geografía de Asia, Libia y Europa y V, 49-54: Descripción de los países entre Sardes y Susa.

${ }^{85}$ How y Wells, op. cit., App., pp. 434-435, parecen olvidar que estamos hablando de un historiador antiguo, al que no tendría que pedírsele cumpliera con esas condiciones, además de que tampoco era un geógrafo, como los que surgieron en la época helenística. 
La orientación espacial en Heródoto

Esbozada en términos muy generales la cuestión del aspecto espacial, ${ }^{86}$ observemos algunos recursos que Heródoto emplea para la elaboración de sus descripciones geográficas. Tomemos como ejemplo un pasaje del libro tercero. En este libro la exposición geográfica aparece como introducción al reinado de Darío (III, 90-117). Se trata de una descripción administrativa del imperio persa que en general no es muy precisa. Al pasar revista a cada una de las provincias tributarias del imperio, Heródoto no sigue un orden geográfico; es decir, no inicia en un territorio determinado y continúa con la región aledaña, sino que en ocasiones menciona consecutivamente provincias muy alejadas entre sí. Al lector antiguo debió de resultarle muy complicado seguir esta clase de informes. No obstante, en algunos casos (III, 93, 1-2) el historiador menciona como puntos de referencia el Ponto Euxino y el Mar Eritreo que dan una idea relativa de la ubicación de los pueblos limítrofes a dichos puntos. Además, Heródoto incluye breves relatos sobre el origen y las costumbres de los pueblos que habitan en el territorio descrito. Es característico el recurso de mencionar al fundador de una ciudad para mejor ubicación de la misma. De esta manera, el auditorio debía recordar al instante el mito que se encontraba detrás del personaje. En el caso de la ciudad de Posideo (III, 91) debió de ser muy conocida la leyenda de Anfíloco, quien participó en la guerra de Troya y que al final fue arrastrado por una tempestad hasta las costas de Panfilia para fundar aquella ciudad. Es norma que Heródoto utilice los vientos y la posición del sol (III, 98, 2) como sistema de orientación espacial. ${ }^{87}$ Otro recurso es el del dativo de "punto

\footnotetext{
${ }^{86}$ Cf. supra, pp. 284 y ss.

${ }^{87}$ Los términos más frecuentes en Heródoto para designar los cuatro puntos

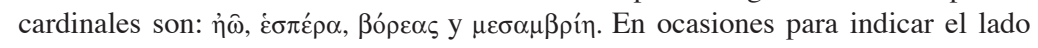


de vista" que tiene la función de establecer la ubicación de un sitio desde la perspectiva del que navega o cruza de un lugar a otro. ${ }^{88}$

Un claro ejemplo de la percepción lineal antigua se presenta cuando el autor desea establecer la separación entre dos territorios, trazando únicamente una extensa línea entre dos puntos. ${ }^{89}$ Esta indicación da una idea aproximada de la región aludida pero no proporciona información sobre el área que cubre esa franja.

Hemos venido diciendo que la ubicación geográfica de los pueblos siempre es relativa y que a ello contribuye en gran medida la mención de ríos y montañas. ${ }^{90}$ Concluyamos con un pasaje que muestra algunos de los elementos indicados:

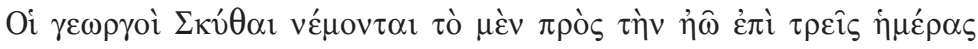

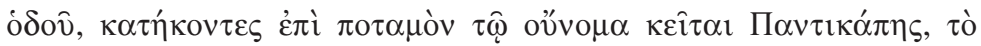

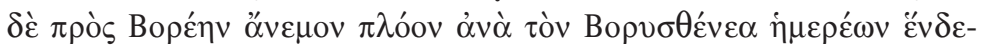
$\kappa \alpha .{ }^{91}$

Hay que notar primero el empleo que hace Heródoto de los vientos y la posición solar como sistema de orientación espacial para indicar las dimensiones del territorio de este pueblo.

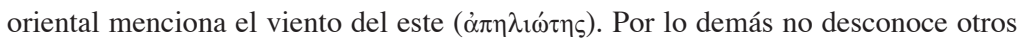

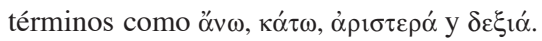

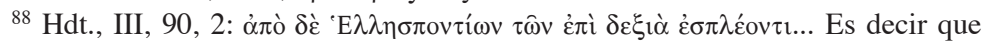
para quien navega del Egeo, por el Helesponto, hasta el mar Negro, este pueblo se encuentra a su derecha. Cf. IV, 34, 2.

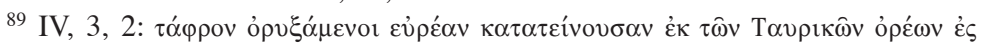

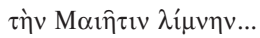

${ }^{90}$ Un método frecuente en Heródoto consiste en emplear las preposiciones

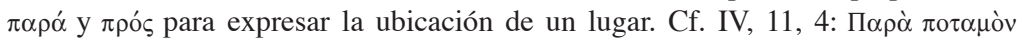

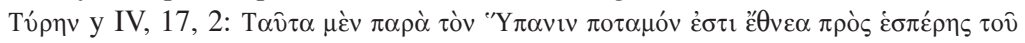
BopvбӨ́́veos.

${ }^{91}$ IV $, 18,2$ : "Estos escitas campesinos [...] habitan lo que está hacia la aurora a tres días de camino extendiéndose hasta el río al que está puesto el nombre de Pantocapes y hacia el viento boreal una navegación de once días hacia arriba del Boristenes. Y la región arriba de éstos es en gran parte desierto". Trad. de Arturo Ramírez Trejo, Heródoto, Historias, vol. II, p. 103. 
Además, sin duda por influencia de los antiguos periplos, menciona la distancia en días para el recorrido. No es común que los historiadores procedan de esta manera; en general, lo importante, sobre todo en la literatura latina, es señalar la sucesión de pueblos y ciudades. Por lo demás, en este pasaje se puede apreciar el importante punto de referencia que constituyen los ríos (Panticapes y Boristenes). Sin embargo, fuera de esos límites no es posible conocer las dimensiones del terreno, pues no existe un referente para ello. Heródoto señala que la región arriba del Boristenes, y por lo tanto de los escitas, "es en gran parte desierto". ${ }^{2}$

\section{Historiografía romana: César. Salustio. Tácito}

\section{A. Función y estructura}

Los Commentarii de Bello Gallico contienen tres grandes pasajes con contenido etno-geográfico: la introducción sobre la ubicación de la Galia (I, 1), ${ }^{93}$ la digresión sobre la geografía de Britania (V, 12-14) y la relación etnográfica sobre Galia y Germania (VI, 11-28). ${ }^{94}$ En el primero, el autor establece los límites geográficos de su empresa bélica y literaria. En reali-

\footnotetext{
${ }^{92}$ A. Ramírez Trejo, ibid.

${ }^{93}$ De este primer pasaje sólo analizaremos la cuestión relativa a la representación espacial, puesto que no puede hablarse aquí de excursus.

${ }^{94}$ Aunque en rigor sólo los dos últimos deben ser considerados como excursus, Panhuis, "Word Order, Genre, Adstratum: The Place of the Verb in Caesar's Topographical Excursus", p. 295, también considera el primero como una digresión legítima. Los dos últimos episodios han sido puestos en duda por la crítica textual. Algunos comentaristas creen que fueron añadidos posteriormente y que, por lo tanto, no son obra de César. Sin embargo, existe otra postura que considera las digresiones como obra del escritor e incluso se afirma que la inclusión de los excursus tiene un propósito bien definido: César intenta ocultar los fracasos militares, o al menos lo insignificante de la campaña, tanto en Britania como en Germania. Sea como fuere, lo cierto es que estas piezas se encuentran, en cada caso, justo a la mitad de la narración de la expedición de César en aquellas regiones.
} 
dad, aquí no hace más que distinguir los tres grandes territorios de la Galia: el de los propios galos, el de los belgas y el de los aquitanos. Sin embargo, es importante observar el método empleado en la ubicación geográfica, pues esencialmente será el mismo en las piezas siguientes.

El primer excursus describe en pocas líneas la ubicación de Britania y el origen y las costumbres de sus pobladores. César introduce la digresión sin ninguna indicación previa, de la misma forma en que procede Heródoto, como ya vimos. Comienza por describir el origen de los britanos. Según refieren sus propios habitantes, los del interior de la isla son indígenas y los de la costa provienen de la Galia. Estos últimos constituyen una enorme población, y su ganado es abundante. Poco después César refiere los tipos de metales que se producen en la región, su moneda, las maderas, la ganadería (liebre, gallina, ganso) y el clima. El siguiente párrafo involucra cuestiones propiamente geográficas: el establecimiento de la forma de Britania y la delimitación del territorio. De paso menciona la isla de Hibernia (Irlanda) y su posición. Por último, el autor vuelve con asuntos etnográficos. Para César los hombres más civilizados son los habitantes de la costa por ser más afines a los galos, en cambio los del interior no practican la agricultura (comen leche y carne, y visten con pieles). La digresión concluye con la exposición de tres costumbres britanas: ellos se untan el cuerpo con cierto tipo de sustancia (vitrum), se rasuran todo el cuerpo, excepto la cabeza y el bigote, y los parientes comparten a las mujeres.

El segundo excursus es un informe acerca de los galos y los germanos con una breve sección sobre la geografía de la selva Hercinia. ${ }^{95}$ César comienza presentando un cuadro de las facciones en las que se dividen los galos (VI, 11-12). Después, sucesivamente, se refiere a las clases sociales galas (VI, 1315), su religión (VI, 16), dioses (VI, 17), costumbres (VI, 19)

\footnotetext{
${ }^{95}$ B.G., VI, 11: “de Galliae Germaniaeque moribus...”.
} 
y leyes (VI, 20). A continuación hace lo propio con el pueblo germano. Resalta la oposición de muchas tradiciones germanas con relación a las galas. Los germanos se dedican por completo a la milicia y la caza y los jóvenes castos son muy apreciados entre ellos (VI, 21). No practican la agricultura y no acostumbran tener un terreno propio (VI, 22). No les gusta tener vecinos, pero se muestran muy amables con los huéspedes (VI, 23). El excursus concluye con una breve reseña de las guerras entre galos y germanos, la ubicación de la selva Hercinia y una exposición de la zoología de la región (VI, 24-28).

Concentrémonos ahora en el excursus de África del Bellum Iugurthinum (17-19.8) de Salustio. Esta digresión junto a la de los "partidos políticos" en Roma (41.1-42.5) supone un corte muy profundo en la narración. A partir de aquí, con la división del territorio de Numidia entre Yugurta y Adérbal, los acontecimientos toman un rumbo que hace necesaria la intervención romana en la región. ${ }^{96} \mathrm{El}$ reparto de las tierras entre los dos descendientes de Micipsa permite a Salustio introducir la digresión y explicar la geografía de la región.

La estructura del excursus es la siguiente: Salustio comienza señalando el objetivo ${ }^{97}$ y el tópico de la dificultad que conlleva tratar este asunto (17.1-2). En párrafos sucesivos expone las ideas acerca de la división del mundo, la situación geográfica de África, su suelo y clima (17.3-5). A continuación menciona algunas características de los habitantes, así como su origen (17.6-7). La parte más extensa está dedicada a una "historia" del origen de los africanos y su asentamiento en el continente (18.1-19.2). Al final, Salustio vuelve a echar mano de la geografía para definir la ubicación de los distintos pueblos sobre el territorio de África (19.3-19.6) y esboza la situación

\footnotetext{
${ }^{96}$ Para Perrochat (citado por Erich Kostermann, C. Sallustius Crispus. Bellum Iugurthinum, p. 87) este excursus tiene la función à provoquer une suspension de l' action pour distinguer différentes périodes de son développement; elles sont avant tout dues au goût personnel de l'auteur.

${ }^{97}$ Bell. Iug., 17.1: "Res postulare videtur Africae situm paucis exponere et eas gentis, quibuscum nobis bellum aut amicitia fuit, attingere".
} 
política de los africanos en la época de la guerra con Yugurta (19.7)..$^{98}$

Según E. de Saint-Denis, el Agricola de Tácito posee numerosas y cuidadas digresiones. ${ }^{99}$ La que nos interesa ahora es la relativa a la etnografía y geografía de Britania (10-12). Este excursus junto a la relación histórica de la provincia hasta la época inmediatamente anterior a la llegada de Agrícola (1317) es un antecedente necesario para señalar la magnitud y el valor de la empresa de la conquista de Britania y la propia participación de este personaje. ${ }^{100} \mathrm{La}$ información que Tácito presenta en esta digresión tiene la finalidad de proporcionar al lector la naturaleza exacta de los logros de su suegro. Creemos que Tácito ha elegido un momento muy oportuno para insertar la digresión, poco antes de relatar la toma del cargo más importante en la carrera de Agrícola, es decir, el gobierno de Britania. Al proceder de esta forma Tácito no hace más que recrear una técnica que ya vimos con Salustio, es decir, el empleo de digresiones para separar los episodios principales del resto de la narración. La estructura del excursus es la siguiente: primero, el proemio; ${ }^{101}$ después Tácito establece la situación geográfica de Britania (10.2-3), comprueba su insularidad y menciona la conquista de las islas Órcadas - u Orkney Islands-, al norte de Escocia (10.4). El historiador utiliza un recurso que luego Amiano Marcelino empleará en varias ocasiones: la inclusión de un excursus dentro de otro. En el caso del Agricola se trata de un breve informe sobre las características del mar al norte de Escocia (10.5-6). Más adelante comienza la relación etnográfica de Britania: origen de sus habitantes (11.1), características físicas y su relación con las regiones cercanas

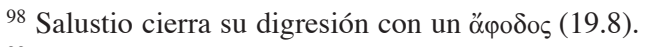

${ }^{99}$ Citado por J. M. Requejo, Cornelio Tácito, Agrícola, Germania, Diálogo sobre los oradores, p. 45.

${ }^{100}$ Cornelii Taciti, De Vita Agricolae, p. 15.

${ }^{101}$ Agr., 10.1: "Britanniae situm populosque multis scriptoribus memoratos... referam".
} 
(11.2), ocupación de la isla por los galos, algunos ritos y su lengua (11.3), y su carácter (11.4). Por último, Tácito refiere algunas cuestiones sobre la milicia y sus aptitudes políticas (12.1-2), el clima de la isla (12.3-4), el suelo y las riquezas marítimas (12.5-6).

\section{B. Contenido}

Establecidas la función y la estructura de cada uno de los excursus, hagamos algunas observaciones en lo que al contenido se refiere. ${ }^{102}$ Lo primero que se advierte es la irregularidad en el cumplimiento de los cinco puntos "reglamentarios" a tratar dentro en un estudio etnográfico. Por una parte, la situación geográfica de la región así como la exposición relativa al origen de los habitantes están presentes en casi todos los excursus. La geografía de la Galia en el caso del De Bello Gallico ya fue establecida en la introducción y por ello no hay necesidad de incluirla en el excursus; asimismo, la omisión de un análisis sobre el origen de los germanos puede explicarse a partir del parentesco que César pudiera observar entre ellos y los galos.

Por el contrario, las cuestiones sobre el clima, recursos naturales y organización política y social no se verifican en todos los excursus. Resulta curioso que el clima sólo sea mencionado por César en la digresión sobre Britania, y por Tácito. La semejanza de juicios hace pensar que este último tuvo en cuenta al general romano al momento de incluir este elemento. ${ }^{103}$ En cuanto a los recursos naturales y los productos agrí-

\footnotetext{
${ }^{102}$ Además de los excursus de los historiógrafos clásicos analizamos el excursus de Amiano sobre los galos (15.9-12). Es necesario aclarar que Amiano Marcelino rebasa con mucho en el resto de los excursus geográficos la cantidad y la variedad de elementos incluidos en su excursus sobre la Galia. Sólo se analiza aquí este pasaje con la finalidad de comparar los distintos estudios sobre una misma región.

${ }^{103}$ César escribe: "loca sunt temperatiora quam in Gallia, remissioribus frigoribus" (V, 12, 6); mientras que Tácito: "asperitas frigorum abest” (XII, 3).
} 
colas de la región sólo César menciona algo más que los demás con relación a Britania; Salustio y Tácito apenas si refieren las características del suelo, y los metales que se producen en el caso del segundo. ${ }^{104}$ Tácito es el único interesado en tratar asuntos relativos a la organización política y militar; por su parte sólo César, con relación a los galos, y Amiano tocan lo referente a la organización social. Es necesario notar la casi sistemática presencia de las líneas introductorias donde el autor expone el objetivo, y en ocasiones, el método a seguir. También es recurrente la descripción de los rasgos físicos de los pueblos. ${ }^{105}$ En uno y otro caso, sólo César omite estos elementos (el primero en el excursus de Britania y el segundo en el de Galia y Germania).

La exposición de las costumbres de los pueblos es imprescindible dentro de las relaciones etnográficas; sin embargo, dentro de los autores seleccionados, sólo César y Amiano la incluyen en su estudio. Por último, es digno de señalarse la presencia de un aspecto importante en los excursus etnográficos dentro de la historiografía latina: la historia de las relaciones entre el pueblo en cuestión y Roma. Este elemento sólo se encuentra en Salustio, César - en el caso de los facciosos galos - y Amiano. Sorprende el que no se incluyan - con excepción de César- cuestiones sobre las divinidades y los sacrificios, así como sobre el vestido y la vivienda. ${ }^{106}$

\footnotetext{
104 Tácito escribe que en Britania se produce el oro y la plata (XII, 6), metales que no son mencionados por César. Por lo demás se cree que con los términos alia metalla Tácito hace referencia a los metales que César refiere; es decir, estaño, bronce y cobre. Cf. C. Tácito, Agrícola, Germania, Diálogo de los oradores, p. 65, n. 45 .

${ }^{105}$ Es interesante el hecho de que sólo Tácito y Amiano describan "psicológicamente" a los pueblos que analizan, autores que han sido señalados como excelentes en el tratamiento de los caracteres.

${ }^{106}$ Aún más, César se destaca por ser el único en dedicar unas líneas a la zoología de Germania.
} 


\section{La orientación espacial}

De la misma forma en que lo hicimos con Heródoto, analicemos ahora algunos de los recursos utilizados por los historiógrafos latinos en los pasajes geográficos. En primer lugar, es necesario señalar que los tres autores emplean la referencia de los cuatro puntos cardinales para la delimitación de la región a describir. Así Julio César para situar la región de los galos, belgas y aquitanos:

Eorum una, pars, quam Gallos obtinere dictum est... vergit ad septentriones. Belgae ab extremis Galliae finibus oriuntur... spectant in septentrionem et orientem solem. Aquitania a Garumna flumine ad Pyrenaeos montes et eam partem Oceani quae est ad Hispaniam pertinet; spectat inter occasum solis et septentriones. ${ }^{107}$

O para establecer los límites de Britania:

Huius lateris alter angulus, qui est ad Cantium... ad orientem solem, inferior ad meridiem spectat... alterum vergit ad Hispaniam atque occidentem solem... Tertium est contra septentriones; cui parti nulla est obiecta terra, sed eius angulus lateris maxime ad Germaniam spectat. ${ }^{108}$

En Salustio los puntos cardinales tienen la función de delimitar el territorio de África:

${ }^{107}$ B.G., I, 3: "Una parte suya [de la Galia], la cual se dijo que poseen los galos... se inclina hacia el septentrión. Los belgas surgen desde los extremos confines de Galia... miran al septentrión y al sol que surge. Aquitania se extiende desde el río Garumna a los montes Pirineos y esa parte del Océano que está hacia Hispania; mira entre el ocaso del sol y el septentrión”. Trad. Rubén Bonifaz Nuño, Julio César, Guerra Gálica, p. 1.

${ }^{108}$ B.G., V, 13: "Un ángulo de este lado, que está hacia Cancio... mira hacia el sol naciente; el inferior, hacia el mediodía. Otro se vuelve hacia Hispania y el sol poniente... El tercero está contra el septentrión; a esa parte ninguna tierra hay interpuesta; pero su otro ángulo mira máximamente hacia Germania”. Trad. Rubén Bonifaz Nuño, op. cit., p. 86. 
Ea [Africa] finis habet $a b$ occidente fretum nostri maris et Oceani, ab ortu solis decliuem latitudinem, quem locum Catabathmon incolae appellant. ${ }^{109}$

Tácito también emplea este sistema de orientación en la definición de Britania:

Britannia... in orientem Germaniae, in occidentem Hispaniae obtenditur, Gallis in meridiem... inspicitur; septentrionalia... vasto atque aperto mari pulsantur.

El uso de los ríos como división entre dos regiones o como puntos de origen para la delimitación ${ }^{110}$ de éstas, se nota sobre todo en la descripción de la Galia y de la selva hercinia:

Gallos ab Aquitania Garumna flumen, a Belgis Matrona et Sequana dividit.

Eorum una, pars, quam Gallos obtinere dictum est, initium capit a flumine Rhodano, continetur Garumna flumine, Oceano, finibus Belgarum, attingit etiam ab Sequanis et Helvetiis flumen Rhenum... Belgae ab extremis Galliae finibus oriuntur, pertinent ad inferiorem partem fluminis Rheni... Aquitania a Garumna flumine ad Pyrenaeos montes et eam partem Oceani quae est ad Hispaniam pertinet... ${ }^{111}$

\footnotetext{
109 Bell.Iug., 17, 4: "Limita [África] al occidente con el estrecho que media entre nuestro mar y el Océano, y al naciente con una extensa superficie en declive, a que sus habitantes nombran Catabatmos”. Trad. Agustín Millares Carlo, Salustio, Guerras de Yugurta, p. 15.

${ }^{110}$ En la descripción de Britania ni César ni Tácito recurren a los ríos para establecer los límites del territorio, quizá por el general desconocimiento que se tenía de ellos. De haberlo hecho, hubiera sido casi imposible transmitir una imagen de la región a un determinado auditorio. Salustio tampoco emplea este recurso en el caso de África.

${ }^{111}$ B.G., I, 3: "Una parte suya, la cual se dijo que poseen los galos, toma inicio desde el río Ródano; es limitada por el río Garumna, por el Océano, por los confines de los belgas; toca también, desde los sécuanos y los helvecios, al río Reno (sic)... Los belgas surgen de los extremos confines de Galia; se extienden hacia la parte inferior del río Reno... Aquitania se extiende desde el río Garumna a los
} 
Oritur [silva] ab Helvetiorum et Nemetum et Rauracorum finibus vectaque fluminis Danubi regione pertinet ad fines Dacorum et Anartium... ${ }^{112}$

Entre geógrafos e historiadores se recurre con frecuencia a imágenes que colaboran con la fijación del mapa mental de una zona geográfica determinada. En el caso de Britania, César menciona que la isla tiene forma de triángulo. ${ }^{113}$ Autores posteriores están de acuerdo con la figura que propone César o que quizá ya había propuesto un autor helenístico. Tácito, sin estar en desacuerdo con la tradición, añade que la isla tiene una forma de hacha romboide con doble eje. ${ }^{114}$ Este es un recurso también muy empleado por Amiano Marcelino como tendremos oportunidad de observar. ${ }^{115}$

El excursus de África tiene la particularidad de contener la descripción de una extensa zona geográfica — casi toda la costa norte de África-. A su vez dicha descripción es "móvil”; es decir, que a diferencia de los otros autores, que únicamente determinan los límites de la región a considerar sin desplazarse hacia otro territorio, Salustio va conduciendo al lector por toda la franja costera del continente mencionando no sólo las regiones existentes sino también los pueblos que ahí se asientan:

montes Pirineos y esa parte del Océano que está hacia Hispania...”. Trad. Bonifaz Nuño, op. cit., p. 1.

${ }^{112}$ B.G., VI, 25: "Surge [el bosque] de los confines de los helvecios y los nemetes y los rauracos, y se extiende en la recta dirección del río Danubio hasta los confines de los dacios y los anartes...”. Trad. Bonifaz Nuño, op. cit., p. 120.

${ }^{113}$ B.G., V, 12-14: "Insula natura triquetra...".

114 Agr., X, 3: "Formam totius Britanniae... auctores oblongae scapulae vel bipenni adsimulavere...”. Para más información sobre la interpretación de este pasaje, cf. Cornelii Taciti, De Vita Agricolae, pp. 168-169. Estrabón (IV, 199) y Pomponio Mela (III, 6, 50) también mencionan la forma triangular de la isla, pero no nos fue posible localizar a algún autor que mencione la figura de "hacha" que según Tácito otros autores proponen.

${ }^{115}$ Cf. infra, pp. 312 y 313. 
Igitur ad Catabathmon, qui locus Aegyptum ab Africa dividit, secundo mari prima Cyrene est, colonia Theraeon, ac deinceps duae Syrtes interque eas Leptis, deinde Philaenon arae, quem locum Aegyptum versus finem imperi habrere Carthaginienses, post aliae Punicae urbes. Cetera loca usque ad Mauretaniam Numidae tenent, proximi Hispania[m] Mauri sunt. Super Numidiam Gaetulos accepimus partim in tuguriis, alios incultius uagos agitare, post eos Aethiopas esse, dein loca exusta solis ardoribus. ${ }^{116}$

El autor comienza la descripción en la región de Catabathmon. De ahí traslada el relato hacia el occidente (Cirene, las Sirtes y Leptis). La expresión secundo mari indica el punto de referencia en la narración. Hasta aquí resulta más o menos clara la relación, pero cuando se menciona a los pobladores más cercanos a Hispania y los que se encuentran después de ellos ya no es posible definir con exactitud su situación geográfica. Esto se debe fundamentalmente a que el autor no cuenta con un punto sobre el cual apoyar su descripción. Si bien recurre a regiones bien o medianamente conocidas como Hispania, Mauritania y Numidia para la ubicación de los pueblos, los términos proxumi, super, post y dehinc indican el desconocimiento de lugares lejanos e inhóspitos.

El método empleado por Salustio será en esencia el mismo que el de Amiano, si bien en muchas ocasiones de forma más desarrollada. Habíamos dicho que la literatura etnográfica desarrolló un método y un esquema para colocar todo el mate-

\footnotetext{
${ }^{116}$ Bell.Iug., 19, 3-6: "De la parte, pues, del Catabatmos, lugar que separa a Egipto de África, ocurre, en primer término, siguiendo la costa, Cirene, colonia de los tereos; más adelante están las dos Sirtes, y entre ellas la ciudad de Leptis; vienen luego los altares de los Filenos, límites del imperio cartaginés por la parte de Egipto, y otras ciudades púnicas. Los númidas poseen los demás lugares hasta la Mauritania; los moros son los más cercanos a España. Al sur de Numidia dícese que viven los gétulos, unos en chozas y otros, más bárbaros aún, vagabundos. Más arriba de éstos se hallan los etíopes, y luego países abrasados por los rayos del sol". Trad. Millares Carlo, op. cit., p. 17.
} 
rial recabado sobre los pueblos. ${ }^{117}$ Junto a ello los etnógrafos crearon un lenguaje técnico. Tópicos y vocablos semejantes empleados en los excursus pueden verificarse en los tres autores así como en Amiano Marcelino. Por ejemplo, el ideal de exactitud y veracidad está expresado por Tácito (rerum fide); el de concisión, por Salustio (quam paucissumis absolvam). ${ }^{118}$ Como ya vimos, constituye un topos preguntarse por el origen de los pueblos, así en Tácito (Ceterum Brittaniam qui mortales initio coluerint) como Salustio (qui mortales initio Africam habuerint). ${ }^{119}$ Los autores también utilizan un cuerpo muy específico de verbos para la descripción geográfica: $o b$ tendere, spectare, vergere, inspicere.

\section{La orientación espacial en Amiano Marcelino}

En términos generales Amiano demuestra un buen sentido de la ubicación en todos sus excursus. ${ }^{120}$ Como producto de sus fuentes - periplos e itinerarios - Amiano proporciona también "distancias exactas" entre dos puntos determinados, por ejemplo la extensión de 23000 estadios de todo el litoral del Mar Negro (22.8.10) o la distancia de 2500 estadios entre el monte Carambis y Criumetopon (22.8.20). ${ }^{121}$ En lo que se refiere a la orientación Amiano emplea, aunque no muy fre-

${ }^{117}$ Cf. supra, pp. 278 y ss.

${ }^{118}$ Cf. supra, pp. 269 y 270.

${ }^{119}$ Cf. R. G., 15.9.2: "super origine prima Gallorum scriptores veteres notitiam reliquere negotii semiplenam...". Hay que decir que un elemento nuevo en Amiano Marcelino es el tópico de tratar una cuestión que entre los antiguos fue desconocida o mal estudiada. Cf. supra, p. 270, n. 27.

${ }^{120}$ En este apartado seguimos muy de cerca los comentarios de G. Sundwall, op. cit., passim.

${ }^{121}$ Cf. también 15.4.3: la circunferencia del Lago Constanza. 15.11.18: distancia entre el golfo de Lyon y Arlés. 23.6.11: extensión del golfo pérsico. 23.6.74: extensión de la costa marítima de Persia desde los montes caspios por el norte y el Nilo por el sur, etc. 
cuentemente, los términos que designan los cuatro puntos cardinales - septentrio, meridies, oriens y occidens-. Resulta más común que el historiador inicie sus descripciones con un punto de referencia específico, y a partir de allí lo relacione con los puntos siguientes. ${ }^{122} \mathrm{Al}$ proceder así Amiano orienta al lector en cada caso según las necesidades de la descripción, en vez de basar todo el relato en un único punto de referencia, como lo hacen normalmente los historiadores analizados arriba. Para relacionar dos puntos en el espacio (lugares, regiones, etc.), Amiano recurre con regularidad a ciertos términos que expresan distancia y dirección. Tal es el caso de superinfra, laevus-dexter brevis-longus prior-post penitus propeprocul angustus-latus parvus-magnus y algunos otros. En la mayoría de las digresiones geográficas se presenta claramente este procedimiento:

Superatis Tauri montis verticibus qui ad solis ortum sublimius attolluntur, Cilicia spatiis porrigitur late distentis dives bonis omnibus terra, eiusque lateri dextro adnexa Isauria, pari sorte uberi palmite viget et frugibus minutis, quam mediam navigabile flumen Calycadnus interscindit. ${ }^{123}$

Hay que notar la mención del Tauro como punto de origen en la descripción. A partir de aquí el relato se extiende hasta las regiones de Palestina, Arabia y Chipre. Según la orientación que presenta en el fragmento - es decir de una posición de oeste a este (de las costas de Anatolia hacia Siria) - Amiano

\footnotetext{
${ }^{122}$ Este procedimiento es patente en 14.8.1, donde Amiano comienza su descripción desde el monte Tauro. En 21.10.3 los montes Hemo y Ródope dan origen al paso del Suco. 22.8.2 comienza con la mención del monte Atos y 31.2.13 con el río Danubio. Para el mismo procedimiento en Salustio, cf. supra, pp. 304 y 305.

123 14.8.1: "Cuando se superan las cumbres del monte Tauro, que se elevan más hacia el este, encontramos Cilicia, con sus amplios y extensos llanos, tierra fértil en productos de todo tipo y, a su derecha, Isauria, de riqueza similar, llena de vides y de abundantes cosechas, surcada en su interior por un río navegable, el Calicadno". Trad. Harto Trujillo, op. cit., pp. 132-133.
} 
sitúa la región de Isauria a la derecha (lateri dextro) de Cilicia. El río Calicadno es un útil punto de referencia para la ubicación "exacta" de Isauria. ${ }^{124}$

Más adelante, dentro del mismo excursus, Amiano intenta establecer la frontera oriental del Imperio:

orientis vero limes in longum protentus et rectum ab Euphratis fluminis ripis ad usque supercilia porrigitur Nili, laeva Saracenis conterminans gentibus, dextra pelagi fragoribus patens. ${ }^{125}$

En este pasaje Amiano hace uso de la línea recta (in longum protentus et rectum) entre el Éufrates y el Nilo para establecer los límites de la región oriental - aun cuando en la realidad no se verificara una línea recta entre los territorios que el autor señala-. Por otro lado, la mención de los ríos precisa el área que se quiere describir. Hay que notar el empleo de los términos laeva-dextra. Según su colocación, es necesario pensar que el autor está ubicado mentalmente en una posición oriente-occidente; de esa forma, los sarracenos, situados a la izquierda de la línea imaginaria entre los dos ríos, están cercanos al Golfo Pérsico, y los pelagi fragoribus se refieren al Mar Negro. Esta ubicación mental es curiosa porque supone un cambio de perspectiva, si la comparamos con la que tenía el autor al principio de la descripción y que era una posición occidente-oriente, o sea la ruta tradicional que los antiguos seguían del Helesponto a Siria. Además de emplear datos históricos en la descripción Amiano presenta características geográficas particulares. Por ejemplo, Fenicia está "inclinada hacia

${ }^{124}$ Cf. supra, pp. 276 y 277. Ahí dijimos que la mención de las ciudades más importantes de una región y los datos históricos que acompañan a cada una tienen la función de ayudar al lector a una mejor localización de la región.

125 14.8.5: "La frontera del oriente, extendiéndose en línea recta, alcanza desde las riberas del río Éufrates hasta las orillas del Nilo, y linda a la izquierda con los pueblos sarracenos y a la derecha con las turbulentas aguas del mar". Trad. Harto Trujillo, op. cit., p. 134. 
el monte Líbano". ${ }^{126}$ Además esta provincia junto a Siria está rodeada "por el río Orontes, que baña los pies del gran monte Casio y desemboca posteriormente en el mar Partenio". ${ }^{127}$

El excursus sobre los hunos también comienza la descripción con la mención de un punto inicial, el río Ister o Danubio. No obstante, el río sólo funciona aquí como el punto medular de vastas y desérticas tierras habitadas por los saurómatas y los alanos y no como el punto de origen de una descripción de mayores dimensiones. ${ }^{128}$

\section{A. El excursus sobre Tracia y el Ponto Euxino (22.8.1-48)}

Ya mencionamos el tema de esta digresión, así como su ubicación en la obra y su función. ${ }^{129}$ En la narración, Juliano ya ha realizado diversas acciones en Dacia y sobre todo en Constantinopla y después nada ocurre en aquellos lugares, sino que el relato comienza a moverse, primero hacia Antioquía, Jerusalén y finalmente Persia. Como sugiere Sundwall, ${ }^{130}$ este excursus no está plenamente justificado, parece que a Amiano se le hubiera ocurrido describir estas regiones mucho después de haber compuesto el resto del libro. Esta es la estructura del excursus:

\footnotetext{
126 14.8.9: "acclinis Libano monti".

127 14.8.10: "provincias quas Orontes ambiens amnis, imosque pedes Cassii montis illius celsi praetermeans, funditur in Parthenium mare". En realidad el Orontes no rodea estas regiones, sino que más bien pasa por en medio de ellas. Este es un claro ejemplo de que las pretensiones literarias de Amiano prevalecen sobre la "exactitud" geográfica.

128 31.2.13: "Abundans Hister advenarum magnitudine fluenti Sauromatas praetermeat ad usque amnem Tanaim pertinentes, qui Asiam terminat ab Europa. hoc transito in inmensum extentas Scythiae solitudines Halani inhabitant".

${ }^{129}$ Cf. supra, pp. 267-276. A. Emmett (citado por Drijvers, op. cit.) hace ver que la introducción de este excursus no indica exactamente de lo que se va a tratar, pues Amiano quiere referirse a Tracia y al Mar Negro y en cambio ocupa un gran espacio la descripción del Egeo.

${ }^{130}$ G. Sundwall, op. cit., p. 623.
} 
1-4 Introducción. Descripción del Egeo

5-8 El Helesponto y la Propóntide

9-13 Geografía del Ponto Euxino

14-19 Costa sur del Ponto. Relato sobre las Amazonas

20-29 Del río Termodón hasta el río Tanais (Don)

30-36 La laguna Meótide (Mar de Azov) y alrededores

37-45 Costa noroeste del Euxino

46-48 Características del Ponto (clima y peces)

Como el excursus sobre las provincias de oriente, éste comienza la descripción de forma similar, pues así como en aquel lugar Amiano iniciaba su descripción a partir del monte Tauro, de la misma forma en esta digresión arranca del monte Atos, punto de referencia inicial en la configuración del mapa conceptual de la región. ${ }^{131}$ De ese modo, consigue delimitar el área descrita y entretejer el punto de origen con el resto del relato.

Al inicio, Amiano establece una línea recta imaginaria entre el Atos y el promontorio del Cafereo, en Eubea. Ésta sólo sirve para delimitar y destacar la ubicación del Mar Egeo, el cual será el verdadero eje de la narración hasta el parágrafo nueve, lugar en el que comienza la descripción del Mar Negro. Cuando es el Egeo el punto de partida, el autor se traslada en la descripción de una orientación norte-sur (Atos-Cafereo) a una orientación este-oeste o derecha-izquierda (Espóradas y Cícladas-Imbros, Ténedos, Lemnos y Tasos). ${ }^{132}$ Así las islas Cícladas y Espóradas quedan del lado derecho en la nueva ubicación y el resto de las islas en el lado izquierdo. Esto busca facilitar las cosas, pues de otra forma sería muy complicado a partir de la primera posición seguir toda la descripción del área. Por otro lado, en este pasaje se puede apreciar que todos

\footnotetext{
131 22.8.2: "Athos in Macedonia mons... et Caphereus euboicus scopulus... licet longo spatio controversi a Thesalo mari distinguunt Aegeum...".

132 22.8.2: "Aegaeum, quod paulatim fusius adulescens, dextra, qua late protenditur, per Sporadas est insulosum atque Cycladas, ideo sic appellatas quod omnes ambiunt Delon partu deorum insignem, laeva Imbrum et Tenedum circumluens et Lemnum et Thasum, quando perflatur, Lesbo inliditur violentius".
} 
los elementos de la descripción colaboran en el determinación de la zona. De una parte se sitúan las Cícladas, por donde el mar tiene su mayor extensión, y de otra se definen sus márgenes hasta Lesbos. Las referencias históricas y mitológicas tienen la función de realzar la importancia de los lugares mencionados, pero sobre todo de proporcionar al lector una ayuda en su localización. Es posible que para un lector de una mediana cultura fuese sabido que los persas atravesaron el monte Atos en su marcha hacia Grecia y que Nauplio luchó en Eubea contra los argivos. Esta información debió ser mucho más útil que hablar en términos de distancias "precisas".

Amiano continúa el relato no con la descripción de Tracia propiamente, como podría esperarse, sino con la de aquellos lugares que baña el Egeo. De esta manera, menciona la Tróade, Ilión, Abdera, Maronea y Eno. Amiano intenta relacionar cada región con un suceso o personaje famoso. Así Ilión es conocida por las hazañas que allí sucedieron, Abdera por ser la patria de Protágoras y Demócrito, y Eno por haber sido una fundación de Eneas. A partir de aquí Amiano se dedica a mencionar las ciudades bañadas primero por el Helesponto y después por la Propóntide (Mar de Mármara). La misma sucesión de ciudades (en el caso del Helesponto: Cinosema, Cela, Sestos y Galípoli de un lado y Dárdano, Abidos y Lámpsaco del otro; en el caso de la Propóntide: Cízico, Díndima, Apamia, Cío y Nicomedia en una dirección y el Quersoneso, Egospótamos, Lisimaquia y Perinto en la otra) y la imagen de la letra griega phi $(\Phi)$ que Amiano emplea en dos ocasiones tienen la finalidad de establecer las dimensiones y la forma del mar. ${ }^{133}$

133 22.8.4: "[Aegeum] ruens in Pontum eiusque partem ad se iungens, in speciem $\Phi$ litterae formatur...". 22.8.6: "et ut effectae plenaeque $\Phi$ litterae figura servetur, in meditullio ipso rotunditatis Proconesus insula est oblonga et Besbicus". Quizá la alusión a la letra phi se ajuste a la descripción que viene a continuación, porque cada uno de los semicírculos formados en la letra podría representar a las ciudades que se encuentran a uno y otro lado de la Propóntide, la cual podría ser la línea transversal en el esquema de la phi, aunque para Amiano esa línea la re- 
Amiano prosigue con la descripción del Mar Negro, cuya forma compara con la figura de un arco escita con su cuerda tensa. ${ }^{134}$ Una vez más el historiador recurre a una imagen para transmitir al auditorio la forme del mar. Al mismo tiempo, procede a establecer sus límites, en esta ocasión empleando los puntos cardinales. ${ }^{135}$ La descripción de las ciudades a la orilla del Mar Negro sigue una dirección contraria a la de las manecillas del reloj, es decir, una dirección este-oeste. Al parecer Amiano adopta aquí el sistema empleado por los periplos más cercanos a su época, pues los más antiguos seguían la dirección de las manecillas. ${ }^{136}$ En esa dirección Amiano va describiendo las riberas del Euxino. Comienza con las provincias de Bitinia, el Ponto y Paflagonia. Menciona las ciudades más importantes y recuerda algún suceso célebre. En la región de los bébrices Pólux venció al tirano Amico, y de Ceraso Lucio Licinio Lúculo trajo la cereza. En este lugar, Amiano abre un breve paréntesis para relatar la historia de las rocas Simplégades. Continúa con la mención de las regiones y ríos situados en el oriente del Mar Negro. Una vez más se produce una pequeña digresión sobre el asentamiento y las guerras de las Amazonas en aquellos lugares. Posteriormente la narración llega

presentan las islas de Proconeso y Bésbico. Por lo demás, la analogía de la phi no está clara para los críticos. J. Rolfe prefiere pensar en una theta.

134 22.8.10: "in speciem Scythici arcus nervo coagmentati geographiae totius adsensione formatur". Cf. 22.8.37. Como Amiano lo indica esta analogía era recurrente en la antigüedad. La mencionaron Estrabón (II, 5, 22), Pomponio Mela (I, 102) y Plinio (IV, 76). Al parecer esta imagen fue extraída de las Historias (III, 63) de Salustio, quien quizá a su vez la heredó de alguna tradición helenística. Sospechamos que la relación entre el Mar Negro y un arco escita es más producto de la imaginación literaria — los escitas son los arqueros por antonomasia- que otra cosa.

135 22.8.11: "et qua sol oceano exsurgit eoo, paludibus clauditur Maeotidos: qua declinat in vesperum, Romanis provinciis terminatur: unde suspicit sidus arctoum, homines alit linguis et moribus dispares: latus eius austrinum molli devexitate subductum". Ha sido señalado como un grave error de orientación el que Amiano coloque la laguna Meótide (el Mar de Azov) al oriente del Mar Negro y no al norte, cf. J. Fontaine, Ammien Marcellin, Histoire, livres XX-XXII, Paris, 1975, n. 659.

${ }^{136}$ J. W. Drijvers, op. cit., passim. 
a la parte norte del mar, la laguna Meótide (Mar de Azov), y a su parte occidental. Amiano finaliza la digresión con una caracterización del Ponto. ${ }^{137}$

Después de la lectura del excursus quedamos desconcertados frente a algunas contradicciones. Parece que la información proporcionada por Amiano presenta las mismas características que la tradición se ha impuesto. No obstante, Amiano parece estar en ocasiones más cerca de los escritos de los geógrafos, como Estrabón, Plinio, Ptolomeo o inclusive los periplos que - y quizá es lo más interesante- de los propios historiógrafos. Pero, por otro lado, parece que el autor sirio no conoce bien la información recabada por aquella vertiente de la tradición, desde la época de las colonizaciones griegas en los VIII y VII a.n.e. hasta Pomponio Mela, como lo podemos notar por el ejemplo del excursus sobre la región del Mar Negro. En ocasiones los datos de Amiano parecen no tener mucho sustento. El orden de las ciudades mencionadas en el informe es erróneo e inclusive llama islas a lugares situados en tierra firme. ${ }^{138}$ En la comparación del Mar Negro con un arco escita, la insuficiencia de distancias exactas o la ambigüedad de los términos dexterlaevus, prope, etc., indican una vaga noción para alguien que, además de haber visto el lugar que describe, se instruyó con diversas lecturas. ${ }^{139}$ Por desgracia no es posible decir con plena seguridad cuáles fueron las fuentes que Amiano tuvo a la mano en el momento de escribir esta digresión. ${ }^{140}$

137 22.8.46: "Omnis autem circumfluo ambitu Pontus et nebulosus est, et dulcior aequorum ceteris et vadosus...".

${ }^{138}$ El caso más relevante es el de las ciudades de Hermonasa y Fanagoro (22. 8.30: "cuius in dextro latere insulae sunt Phanagoris et Hermonassa studio constructae Graecorum").

${ }^{139}$ Recuérdese el ideal de conocimiento "pleno": "visa vel lecta... monstrare". Cf. supra, pp. 269 y 270, ns. 25-27. Esta última indicación de Amiano resulta más desconcertante cuando se descubre que una buena parte de los datos del excursus fue extraida de fuentes escritas y casi nada de la experiencia.

${ }^{140}$ Cf. Drijvers, op. cit., passim. En términos generales se cree que empleó las collectanea rerum memorabilium de Solino, las Historias de Salustio, en cuyo 
Sin embargo, aunque el historiógrafo sigue - como dijimos, en ocasiones con deficiencia - en la estructura y en el contenido algunas fuentes escritas de tipo "científico" como las mencionadas, su tratamiento de los datos geográficos, etnográficos, mitológicos e históricos es algo distinto al de aquellos autores. Y esto es natural, pues su obra pertenece al género historiográfico y es claro que Amiano no desea componer un tratado especializado de geografía. En la historiografía el componente geográfico sólo es un auxiliar del discurso histórico. Y es aquí - por más extraño que parezca - donde tenemos que mencionar las diferencias que guarda con el género historiográfico. Podemos decir que Amiano tiene un respeto muy grande por la tradición e intenta situarse en ella. Procede igual que los historiógrafos clásicos en muchos aspectos. Incluye las digresiones de la misma forma que el preámbulo del discurso histórico. No podemos decir de manera concluyente hasta qué punto los "clásicos" - César, Salustio, Tácito - intentaron congraciarse con su público. Es verdad que proporcionan datos sobre lugares lejanos y desconocidos y sobre las exóticas costumbres de sus habitantes. No obstante, en la mayoría de los casos no van más allá, no aderezan sus narraciones con historias, mitos y elementos poéticos de la misma forma como lo hace Amiano Marcelino, sin mencionar que la amplitud de

libro tercero el autor incluyó un excursus sobre el Mar Negro, la Naturalis Historia de Plinio y algunos periplos. El informe geográfico guarda una especial relación con los datos aportado por Plinio en el libro cuarto de su historia. El gran número de semejanzas revela que Amiano basó su relato casi exclusivamente en fuentes escritas. He aquí algunas de las alusiones plinianas en el excursus de Tracia:

- Causa del término Cíclada aplicado a las islas: Pl., IV, 74 = Amm., 22.8.2.

- Jerjes tiende un puente entre Asia y Europa: Pl., IV, 75 = Amm., 22.8.4.

- Etimología del Ponto Euxino: Pl., IV, 76 = Amm., 22.8.33.

- El arco escita: Pl., IV, 76 = Amm., 22.8.10.

- Circunferencia del Ponto: Pl., IV, 77 = Amm., 22.8.10.

- Cinosema, sepulcro de Hécuba: Pl., IV, 49 = Amm., 22.8.4.

- Las Simplégades: Pl., IV, 92 = Amm., 22.8.14.

- El nacimiento del Danubio y sus 60 afluentes: Pl., IV, 79 = Amm., 22.8.44. 
sus piezas "excursivas" rebasa por mucho a la de los historiógrafos anteriores. ${ }^{141}$

Más que pensar en otras posibles causas estamos de acuerdo en que el objetivo principal de estas piezas es simplemente lograr el entretenimiento del público. ${ }^{142}$ Con seguridad el auditorio no pensaba encontrar en esta clase de relatos un conocimiento científico de la geografía, sino historias entretenidas que en muchos casos le eran familiares. Además de lo dicho, la naturaleza fundamentalmente literaria del excursus está indicada por algunas alocuciones que el propio Amiano introduce, por ejemplo con ocasión del Bósforo ${ }^{143}$ y las rocas Simplégades ${ }^{144}$ o por el uso de términos exclusivamente poéticos. ${ }^{145}$

Con todo lo dicho parece razonable pensar que nos encontramos con piezas literarias. El propósito de Amiano fue ofrecer un texto entretenido, ameno para el auditorio. Con relación a la eficiencia de sus descripciones geográficas no nos queda sino aventurarnos en el terreno de la suposición. No sabemos qué pensar con relación a los "doctos", a los escritores de geografía

\footnotetext{
${ }^{141}$ Aunque creemos que esto debe adjudicarse también a las "necesidades de los tiempos", que condicionaban el relato histórico de las Res Gestae, cuando una buena cantidad de pueblos extranjeros amenazaban con penetrar (y en muchos casos ya lo habían hecho) los territorios romanos. Sería interesante averiguar hasta qué punto la obra de Amiano Marcelino fungía como herramienta de los servicios "de inteligencia" romana — y si había algo parecido a ésta—. De haber sido así, parece pobre la información que proporciona. En definitiva ¿Qué sabían los romanos de sus vecinos? Nos sentimos tentados a responder que casi nada.

${ }^{142}$ Ésta es la tesis de J. W. Drijvers, op. cit., passim.

143 22.8.13: "hac causa Bospori vocitati, quod per eos quondam Inachi filia mutata, ut poetae locuntur, in bovem ad mare Ionium permeavit".

144 22.8.15: "hi scopuli cum eos Argo prima omnium navis Colchos ad direptionem aurei properans velleris praeterisset innoxia, inmobiles turbine circumfracto stetere concorporati, ut eos aliquando Ivisse diremptos nulli nunc conspicantium credant, nisi super hoc congruerent omnes priscorum carminum cantus".

${ }^{145}$ Como la expresión "iamque mitescens in aequoream panditur faciem", donde la palabra aequoreus es empleada casi exclusivamente por Virgilio, Ovidio y Marcial.
} 
científica - Hiparco, Eudoxo, Eratóstenes - , pero es muy probable que los historiógrafos, aun cuando creamos que conocieron personalmente - en parte o en su totalidad - los territorios que describen, no tenían una noción siquiera coherente de la forma o las dimensiones de tierras determinadas. En cuanto al público receptor de estos textos no podemos decir sino que se encontraba en un estado de mayor "incertidumbre". Un romano que leyera o escuchara un relato sobre la geografía de Persia, Egipto o el área que rodea el Mar Negro debía quedar literalmente en tinieblas, sin tener una mínima idea de dónde podían quedar esos territorios o qué extensión pudieran tener. Imaginamos que las personas de aquellos tiempos debieron experimentar la misma sensación con el nombre "Britania" o "Persia" que todavía hace pocos siglos o incluso nosotros mismos tenemos con las palabras "El Dorado" o "Aztlán" —eliminando el hecho de que ahora creemos que éstos son lugares legendarios o ficticios-. Si para un lector moderno resulta casi imposible ubicarse en una narración como la de Amiano Marcelino - un lector que tiene configurado en su mente un mapa del mundo o de determinadas regiones - ahora imaginemos a los antiguos. ${ }^{146}$

\section{BIBLIOGRAFÍA}

\section{Fuentes primarias}

Amiano Marcelino, Historia, ed. Ma. Luisa Harto Trujillo, Madrid, Akal (Clásica), 2002, 971 págs.

146 Por supuesto, no compartimos la opinión de la superioridad del hombre posmoderno - ése menos que ninguno- con relación al antiguo. Creemos que es una polémica estéril. Al contrario, para tratar de comprender mejor esta cuestión pensemos en lo "antiguo" del hombre de hoy en su capacidad de orientación, un mexicano por ejemplo, cuando se le pide — con las debidas excepciones - que configure en su mente la ubicación de Turkmenistán o Burundi o a un australiano la ubicación de México. 
Ammianus Marcellinus, ed. and tr. J. C. Rolfe, London, Loeb Classical Library, 1982-1986, 3 vols.

Ammien Marcellin, Histoire I: Livres 14-16, ed. et trad. E. Galletier et J. Fontaine, Paris, Société Guillaume Budé (Les Belles Lettres), 1968.

Cesar, Guerre de Gaules, ed. et trad. L. A. Constans, París, Les Belles Lettres, v. II, livres V-VIII.

Corneli Taciti De Vita Agricolae, ed. R. M Ogilvie and Sir Ian Richmond, Oxford, Oxford University Press, 1967.

Cornelio TÁcito, Agrícola, Germania, Diálogo sobre los oradores, introducciones, trad. y notas J. M. Requejo, Madrid, Gredos (Biblioteca Clásica Gredos, 36), 226 págs.

CoRnelius TaCitus, Germania, Herausgabe und Übersetzung von Alfons Städele, Düsseldorf-Zürich, Artemio \& Winkler Verlag, 1999.

Estrabón, Geografía, libros I-II, tr. y notas J. L. García Ramón y J. García Blanco, Madrid, Gredos (Biblioteca Clásica Gredos, 159), 1991.

Heródoto, Historias, intr., trad. y notas Arturo Ramírez Trejo, México, Universidad Nacional Autónoma de México (Bibliotheca Scriptorum Graecorum et Romanorum Mexicana), 1984, vols. II y III.

-, Historia, libros I-II, tr. y notas Carlos Schrader, Madrid, Gredos (Biblioteca Clásica Gredos, 3), 1992.

-, Historia, libros VIII-IX, tr. y notas Carlos Schrader, Madrid, Gredos (Biblioteca Clásica Gredos, 130), 1989.

Julio César, Guerra Gálica, intr., trad. y notas Rubén Bonifaz Nuño, México, Universidad Nacional Autónoma de México (Bibliotheca Scriptorum Graecorum et Romanorum Mexicana), 1994.

Quintiliano de Calahorra, Sobre la formación del orador. Obra Completa, Salamanca, Universidad Pontificia de Salamanca, 1999, tomo II, pp. 95-101.

Salustio, Guerra de Yugurta, intr., trad. y notas Agustín Millares Carlo, México, Universidad Nacional Autónoma de México (Bibliotheca Scriptorum Graecorum et Romanorum Mexicana), 1998.

TACite, La Germanie, ed. et trad. Jacques Perret, París, Société d’Édition "Les Belles Lettres", 1949, 111 págs.

\section{Fuentes secundarias}

A Commentary on Herodotus, intr. and app. W. W. How y J. Wells, Oxford, Oxford University Press, 1964, 2 vols.

Albrecht, Michael von, Historia de la literatura romana, Barcelona, Herder, 1999, 2 vols. 
Beristáin, Helena, Diccionario de Retórica y Poética, México, Porrúa, 1998.

Blockley, R. C, Ammianus Marcellinus. A study of his Historiography and Political Thought, Bruselas, Col. Latomus, t. 141, 1975.

BroK, M. F. A., "Die Quellen von Ammians Exkurs über Persien”, Mnemosyne, XXVIII, 1975, pp. 47-56.

CAmus, P.-M., Ammien Marcellin témoin des courants culturels et religieux à la fin de Ivè siècle, Paris, Les Belles Lettres, 1967.

CAPE, Robert W. Jr., "Persuasive history: Roman rhetoric and historiography", en William J. Dominik (ed.), Roman Eloquence, Rhetoric in Society and Literature, London/New York, Routledge, 1997, pp. 212228.

CichockA, H., "Die Konzeption des Exkursus im Geschichtswerk des Ammianus Marcellinus", Eos, 63, 1975, pp. 329-340.

Dilke, O. A. W., Greek and Roman Maps, Ithaca, Cornell University Press, 1985.

Downs, Mary E., "Spatial Conception in the Ancient Geographers and the Mapping of the Hispania Baetica", Classical Bulletin, 1996, 72 (1), pp. 37-49.

DrIJVERS, J. Willem, "Ammianus Marcellinus on the Geography of the Pontus Euxinus", Histos, 1998. (www.dur.ac.uk/Classics/histos/1998/drijvers.html).

DriJvers, Jan W., and David Hunt (eds.), The Late Roman World and its Historian. Interpreting Ammianus Marcellinus, London/New York, 1999.

GERRIT, Jan, “Geographical digressions in Ammianus Marcellinus’ History"

(http://odur.let.rug.nl/ drijvers/ammianus/contributions/geography. htm)

Kostermann, Erich, C. Sallustius Crispus. Bellum Iugurtinum, Heidelberg, Carl Winter, Universitätsverlag, 1971.

Laistner, M. L. W., The Greater Roman Historians, Berkeley/Los Angeles, University of California Press, 1963, 196 págs.

López Ramos, Jorge A., El método historiográfico de Amiano Marcelino: El excursus etnográfico-geográfico en las Res Gestae (Tracia y el Mar Negro 22.8.1-48), México, Universidad Nacional Autónoma de México [tesis de licenciatura], 2005.

LucE, T. J., The Greek Historians, London/New York, Routledge, 1997.

Martínez PAstor, M., "Amiano Marcelino, escritor romano del s. IV. Perfil literario”, Estudios clásicos, 102 (1992), pp. 91-115.

PANHUIS, Dirk, "Word Order, Genre, Adstratum: The Place of the Verb in Caesar's Topographical Excursus", Glotta, 49, 1981, pp. 295-308. 
SabBah, G., La méthode d'Ammien Marcellin. Recherches sur la construction du discours historique dans les "Res Gestae", Paris, Les Belles Lettres, 1978.

Rebenich Stefan, "Historical Prose", en Stanley E. Porter (ed.), Handbook of Classical Rhetoric in the Hellenistic Period 330 B.C.-A.D. 400, Boston/Leiden, Hill Academia Publishers, 2001, pp. 265-337.

Sundwall, Gavin A., "Ammianus Geographicus", American Journal of Philology, 117 (4), 1996, pp. 619-643.

TALBERT, Richard J. A., "Review of Greek and Roman Maps", Journal of Roman Studies, 77 (1987), pp. 210-212.

-, "Rome's Empire and Beyond: The Spatial Aspect", en E. W. Leach (ed.), The Rhetoric of Space: Literary and Artistic Representations of Landscape in Republican and Augustan Rome, Princeton, 1988.

WIJMA, Sara, "Etnographical digressions. Barbarians in Ammianus Marcellinus' Res Gestae".

(http://odur.let.rug.nl/ drijvers/ammianus/contributions/geography. $\mathrm{htm})$ 